\title{
3D In-core Fuel Management Optimization for Breed-and-Burn Reactors
}

Jason (Jia) Hou, ${ }^{1}$ Staffan Qvist, ${ }^{2}$ Roger Kellogg, ${ }^{3}$ and Ehud Greenspan ${ }^{1}$

${ }^{1}$ Department of Nuclear Engineering, University of California, Berkeley, Berkeley, CA 94720, U.S.A.

${ }^{2}$ Department of Physics and Astronomy, Uppsala University, Sweden, Ångström Lab, Lägerhyddsvägen 1, 75237 Uppsala, Sweden

${ }^{3}$ Nuclear Engineering Division, Argonne National Laboratory, Argonne, IL 60439, U.S.A.

Corresponding author: Jason Hou

3115 B\&AA Etcheverry Hall, University of California, Berkeley, Berkeley, CA 74720

Email: jasonhou@berkeley.edu 


\section{D In-core Fuel Management Optimization for Breed-and-Burn Reactors}

Breed-and-burn $(B \& B)$ reactors are a special class of fast reactors that are designed to utilize low grade fuel such as depleted uranium without fuel reprocessing. One of the most challenging practical design feasibility issues faced by $\mathrm{B} \& \mathrm{~B}$ reactors is the high level of radiation damage their fuel cladding has to withstand in order to sustain the $\mathrm{B} \& \mathrm{~B}$ mode of operation - more than twice the maximum radiation damage cladding materials were exposed to so far in fast reactors. This study explores the possibility of reducing the minimum required peak radiation damage by employment of 3-dimensional (3D) fuel shuffling that enables a significant reduction in the peakto-average axial burnup, that is, more uniform fuel utilization. A new conceptual design of a B\&B core made of axially segmented fuel assemblies was adopted to facilitate the 3D shuffling. Also developed is a Simulated Annealing (SA) algorithm to automate the search for the optimal 3D shuffling pattern (SP). The primary objective of the SA optimization is to minimize the peak radiation damage while its secondary objective is to minimize the burnup reactivity swing, radial power peaking factor and maximum change of fuel assembly power over the cycle. Also studied is the sensitivity of the 3D shuffled core performance to the number of axially stacked sub-assemblies, core height and power level.

It was found that compared with the optimal 2-dimentional (2D) shuffled core, the optimal 3D shuffled B\&B core made of four $70 \mathrm{~cm}$ long axially stacked subassemblies and 12 radial shuffling batches offers a $1 / 3$ reduction of the peak radiation damage level - from 534 down to 351 displacements per atom (dpa), along with a $45 \%$ increase in the average fuel discharge burnup, and hence, the depleted uranium utilization, while satisfying all major neutronics and thermal-hydraulics design constraints. For the same peak dpa level, the 3D shuffling offers more than double the uranium utilization and the cycle length relative to $2 \mathrm{D}$ shuffling. The minimum peak radiation damage is increased to 360 or to 403 dpa if the core is made of, respectively, three $-70 \mathrm{~cm}$ or two $-140 \mathrm{~cm}$ long axially stacked subassemblies. Reducing the length of the subassemblies of $\mathrm{B} \& \mathrm{~B}$ cores made of three-segment assemblies from $70 \mathrm{~cm}$ to 60 or $50 \mathrm{~cm}$ results in an increase in the peak radiation damage from 360 dpa to, respectively, 368 and 397 dpa. 
Keywords: breed-and-burn reactor; peak radiation damage; 3D fuel shuffling optimization; simulated annealing; optimal core design

\section{Introduction and Research Objective}

Present day commercial Light Water Reactors (LWRs) can extract only $\sim 0.6 \%$ of the potential energy that is available in the natural uranium mined for making LWR fuel. Approximately $90 \%$ of the unused uranium goes to the depleted uranium (DU) stream of the enrichment process and $\sim 95 \%$ of the enriched uranium is left in the used nuclear fuel (UNF). Fast Breeder Reactors (FBRs) can, in principle, fission almost all the DU "waste", although high uranium utilization cannot be achieved in a single irradiation campaign because the radiation damage accumulated by the fuel and cladding challenges the mechanical integrity of the fuel rod. Consequently, the approach that enables attaining high uranium utilization also involves multiple fuel recycling. Fuel recycling includes removal of the fuel cladding, removal of the fission products, addition of some DU make up fuel, fabrication of new fuel assemblies and reloading them into the reactor core for another irradiation cycle. Such recycling is commonly required for every $10 \%$ to $15 \%$ fissions per initial heavy metal atom (FIMA), depending on the core neutron spectrum and fuel enrichment. Although technically feasible, the fuel recycling was not acceptable to many U.S. administrations and by other countries due to economic viability and proliferation concerns.

FBRs could, in principle, also operate without fuel recycling. That is, using a oncethrough fuel cycle as do the majority of LWRs. Although the standard FBR discharge burnup of 10\% to 15\% FIMA is two to three times higher than that of LWRs, the uranium utilization of a once-through FBR is not significantly different from that of a once-through LWR because the level of uranium enrichment required to achieve criticality in the FBR is often three times that required to fuel the LWR.

To achieve significant uranium utilization without resorting to fuel recycling, special class of fast reactors known as Breed-and-Burn (B\&B) reactors has been proposed and studied since the 1950s. The unique feature of a B\&B reactor is that it can breed plutonium in depleted or natural uranium feed fuel and then fission a significant fraction of 
the bred plutonium without having to reprocess the fuel. Once the initial criticality is established with the assistant of either enriched uranium (EU) or plutonium with or without minor actinides, the $\mathrm{B} \& \mathrm{~B}$ reactor is capable of continuing its operation fed only with fertile fuel such as DU or natural uranium.

There are two basic variants of B\&B reactors: Travelling Wave Reactors (TWRs) and Stationary (or Standing) Wave Reactors (SWRs). In TWRs, like the CANDLE reactor concept [1] and the one proposed by Teller et al. [2], the breeding and burning wave travels axially through the long core from one end to the other. In SWRs, like the one presently being pursued by TerraPower [3] [4], the location of the fission reaction in the core is maintained nearly stationary by adequate radial, i.e., 2-dimensional (2D) shuffling of fuel assemblies. The TWR concept is considered difficult to implement due to its poor neutron economy and excessive level of radiation damage. Therefore, this study focuses on the SWR type of B\&B reactor and its fuel shuffling strategy.

In order to sustain the B\&B mode of operation by feeding the core with fertile fuel such as DU, the burnup the fuel needs to accumulate has to exceed a certain threshold, which strongly depends on the core neutron balance. In a sodium-cooled metallic-fueled $\mathrm{B} \& \mathrm{~B}$ core featuring high fuel volume fraction and low-leakage, the minimum required peak burnup is above $20 \%$ FIMA and the corresponding peak radiation damage of the fuel cladding is in the vicinity of 500 displacements per atom (dpa). [5] The maximum radiation damage cladding materials were exposed to so far in fast reactors is $200 \mathrm{dpa}$, experienced by the ferritic-martensitic steel HT-9 in the Fast Flux Test Facility (FFTF) [6]. This means that the SWRs cladding material must withstand a radiation damage more than double the level that has been proven feasible. A combination of development of advanced structural and fuel materials and irradiation experiments are likely to increase the permissible clad radiation damage beyond 200 dpa but proving the practicality and licenceability of cladding material up to $\sim 500$ dpa may take significant time and resources.

Three approaches for operation in the B\&B mode without exceeding the $200 \mathrm{dpa}$ constraint had recently been investigated: (1) reconditioning the fuel whenever the cladding reaches $200 \mathrm{dpa}$. The function of the reconditioning is to remove the cladding, remove the 
gaseous and some volatile fission products, and load the fuel into a new cladding [7]. (2) Double-clad the fuel [8] after removal of the gaseous fission products. (3) Using excess neutrons from transmutation of trans-uranium elements from LWR UNF to drive a subcritical B\&B blanket up to 200 dpa [9].

The overall objective of this paper is to investigate a different approach for reducing the peak minimum required radiation damage level - use of 3-dimensional (3D) in-core fuel management strategy to reduce the axial variation of the discharge burnup and, thereby, reduce the peak burnup and corresponding peak radiation damage. In the $2 \mathrm{D}$ shuffled system, as the plutonium builds up near the axial center faster than at the bottom and top of the fuel assembly, the axial power and burnup distribution in B\&B cores is significantly more centrally peaked than in conventional (uniform axial composition) sodium-cooled fast reactor (SFR) cores. In a typical low-leakage B\&B core the peak-to-axially average discharge burnup can far exceed 2.0. If the axial profile of burnup or fast fluence can be flattened down to close to 1.0, the peak dpa level may be reduced significantly. An engineering approach to facilitate 3D fuel shuffling has been proposed in a previous study. [10] [11] That preliminary study concluded that the optimal 3D shuffling pattern (SP) offers an approximately $30 \%$ reduction in the peak radiation damage while increasing the fuel utilization relative to a $2 \mathrm{D}$ shuffling.

However, the previous study was based on a user specified trial-and-error approach and was limited to few trials applied to a single core. The 3D SP optimization presents a large decision space - for the reference core given in Ref. [5] that features 12-batches and 4 axially stacked subassemblies there are on the order of $10^{61} \mathrm{SP}$ combinations. Hence, an exhaustive search is not feasible since it is extremely computationally expensive. Moreover, the optimal core design should meet several constraints including the burnup reactivity swing, radial power peaking factor and relative assembly power change over the cycle. This makes a manual selection of SP impractical. In addition, the optimal SP is highly sensitive to the core dimensions and number of radial and axial shuffling zones. Thus, an automated optimization capability that is able to account for all the constraints is desirable. 
The first objective of this study was to develop an automated methodology for the optimization of in-core fuel management for B\&B reactors, for both $2 \mathrm{D}$ and 3D shuffling strategies that is able to account for multiple design constraints. Generic Algorithm (GA) has been successfully applied to in-core fuel management optimization of, primarily, light water reactors [12] [13] [14] as well as for a self-sustaining LMFBR design. [15] [16] Simulated Annealing (SA), a close relative to GA, is another stochastic approach to largescale combinatorial optimization and has proven to be extremely robust in determining families of near-optimum decision variables in the in-core fuel management problems. [17] [18] [19] Although SA and GA are often viewed as separate, competing paradigms in the field of modern heuristics, the key difference between the two methods is the mechanism of generating a new solution from an existing one. While GA generates a new solution guess by combining several prior solutions, SA creates a new solution by modifying only the most recent solution with a local move. In the current optimization problem, the decision variable - the SP, is based on the shuffling of fuel batches rather than of individual assemblies. As a typical B\&B core batch contains tens of fuel assemblies, the impact of SP modification on the core characteristics is much larger than that with single assembly-based $\mathrm{SP}$, creating a much more nonlinear decision space. As a result, the "crossover" between different solutions in GA becomes less important in the generation of new solutions. The SA algorithm was adopted as the optimization method for this study.

The second objective of this study was to quantify the improvements in B\&B core performance made possible by $3 \mathrm{D}$ fuel shuffling and to investigate the dependence of these improvements on the number of axially stacked subassemblies, core power level and core dimensions.

Section 2 provides a detailed description of the reference B\&B core design that features $2 \mathrm{D}$ shuffling, the engineering solution to implement the $3 \mathrm{D}$ shuffling in $\mathrm{B} \& \mathrm{~B}$ cores, and the modeling methodology used in this work. The stochastic SP optimization methodology based on SA and the improvements of the core performance resulting from its application to the 2D/3D shuffled B\&B core are then discussed in Section 3 and 4, respectively. Section 5 explores the 3D shuffled core performance sensitivity to the SP 
simplification, core power, and core size. Last, the general conclusion of the study and future work are provided in Section 6.

\section{Breed-and-burn Reactor with 3D Fuel Shuffling}

\subsection{Reference 2D shuffled core description}

The reference $\mathrm{B} \& \mathrm{~B}$ core concept upon which the $3 \mathrm{D}$ shuffled core were developed in this study is a large SFR fed with DU with $0.25 \%{ }^{235} \mathrm{U}$. The unirradiated nominal fuel density is $18.66 \mathrm{~g} / \mathrm{cm}^{3}$ at $800 \mathrm{~K}$, and a smear density of $75 \%$ is assumed to accommodate the fuel swelling with burnup. The cladding material, which is the ferritic-martensitic alloy HT-9, and the coolant have densities of 7.87 and $0.830 \mathrm{~g} / \mathrm{cm}^{3}$, respectively, both at $800 \mathrm{~K}$. The effective core height is $300 \mathrm{~cm}$ and equivalent diameter of the simulated core is $\sim 493 \mathrm{~cm}$, giving a total active core volume of $57.19 \mathrm{~m}^{3}$, and a volumetric power density of 52.45 $\mathrm{MW} / \mathrm{m}^{3}$ for a total core thermal power of $3000 \mathrm{MW}$. This reference design adopts the vented fuel rod concept [20]. The diving bell type ventilating device allows the release of the fission gas, but prevents the reverse-flow of the coolant into the fuel pin. [20] Venting the released fission gases from the fuel pin into the primary reactor coolant will maintain cladding stresses at low levels to high burnup. The fraction of core volume that is required for the control system was not accounted for in the preliminary core design because the required number of control assemblies cannot be estimated before detailed calculation for safety parameters is performed. The general characteristics and assumed volume fraction of the active core ingredients are presented in Table 1.

Table 1 Main parameters of reference B\&B core

\begin{tabular}{|l|l|}
\hline Thermal power $(\mathrm{MW})$ & 3000 \\
\hline Core equivalent radius $(\mathrm{cm})$ & 246.34 \\
\hline Active fuel length $(\mathrm{cm})$ & 300 \\
\hline Gas plenum height $(\mathrm{cm})$ & 100 \\
\hline Feed fuel & $\begin{array}{l}\text { DU }\left(0.25 \%{ }^{235} \mathrm{U}\right) \text { with } 75 \% \\
\text { smear density }\end{array}$ \\
\hline Coolant & Sodium \\
\hline
\end{tabular}




\begin{tabular}{|c|c|c|}
\hline Inlet/outlet coc & int temperature $\left({ }^{\circ} \mathrm{C}\right)$ & $355.0 / 506.8$ \\
\hline $\begin{array}{l}\text { Structural mate } \\
\text { wire-wrap, refl }\end{array}$ & $\begin{array}{l}\text { al (cladding, duct, } \\
\text { tor pin) }\end{array}$ & HT-9 \\
\hline Fuel assembly & Fuel & 40.70 \\
\hline $\begin{array}{l}\text { volume } \\
\text { fraction }(\%)\end{array}$ & Gap & 13.57 \\
\hline & Cladding+Wire & 13.04 \\
\hline & Duct & 6.28 \\
\hline & Coolant & 26.41 \\
\hline Density (g/cc) & Fuel (theoretical) & 18.99 \\
\hline & Cladding & 7.87 \\
\hline & Coolant & 0.83 \\
\hline
\end{tabular}

In fast reactors, the mean free path for absorption of the large majority of the neutrons far exceeds the dimension of the unit cell. Consequently, it is common to model the core as homogenized; that is, compositions of fuel, coolant, gap and structural materials are mixed together within the fuel assembly by volume weighting.

In order to further reduce the modeling effort of this feasibility study, the assemblybased hexagonal $\mathrm{B} \& \mathrm{~B}$ core is represented in $R-Z$ geometry, which consists of a number of equal-volume concentric fuel batches, each made of several axial regions to account for axial power and burnup variation. A schematic side view of the $2 \mathrm{D}$ shuffled core is given in Figure 1, where the center of the core is at the left edge of the figure and fuel batches are separated by vertical lines in the active core region. It was estimated in previous studies that the relative errors in the multiplication factor $k_{\text {eff }}$ introduced by the cylindrical modeling of the $\mathrm{B} \& \mathrm{~B}$ core is between $0.02 \%$ and $0.2 \% \Delta k / k$, when compared with the assembly-level core model. [21] This error partially stems from the radial power distribution differences between the two models - in the cylindrical core model all the assemblies of a given batch are depleted with the same power level while in the assembly-based core model, a different power level is assigned to each fuel assembly. This approximation is considered acceptable for a study aimed at estimating the relative differences between 3D and 2D fuel shuffling on $\mathrm{B} \& \mathrm{~B}$ core characteristics. 


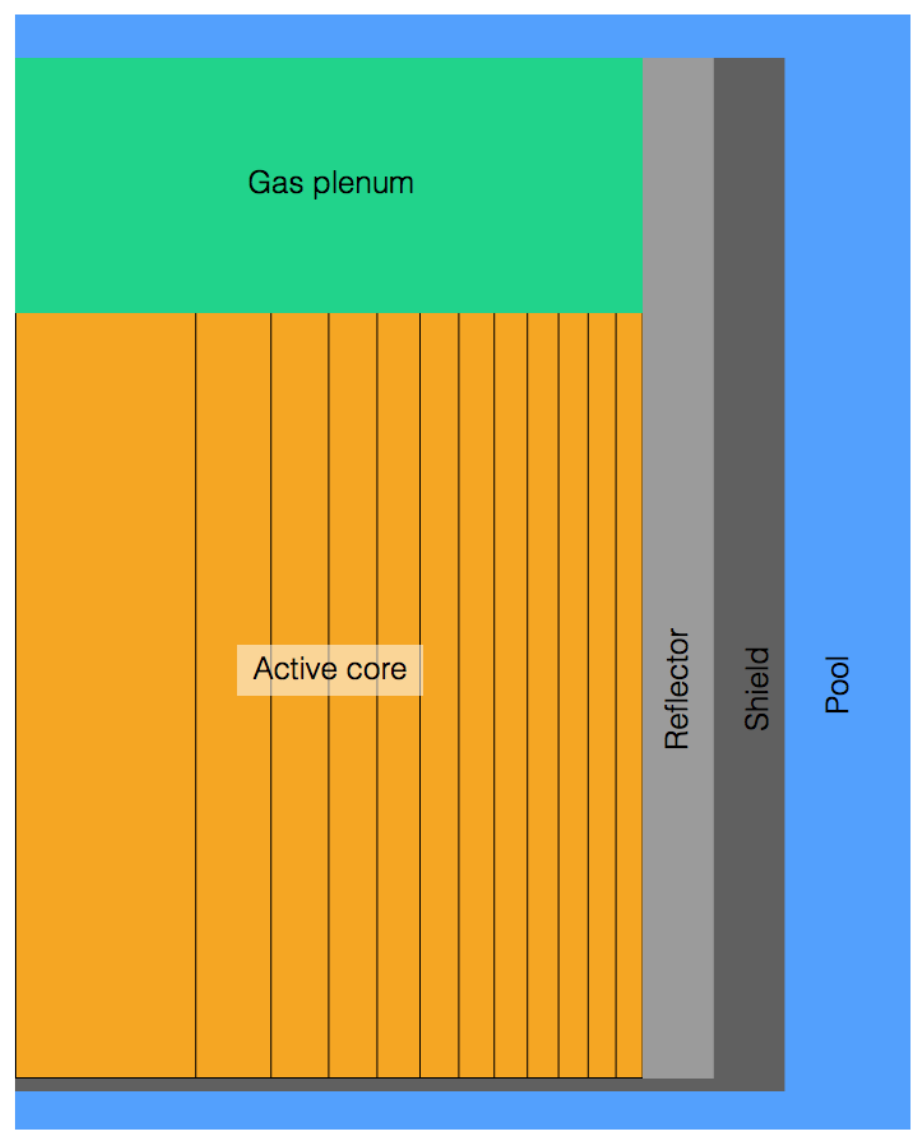

Figure 1 Schematic layout of cylindrical 2D shuffled reference B\&B core.

\subsection{Engineering solution for 3D fuel shuffling}

This section introduces the perceived design of the fuel rods and fuel assemblies to facilitate the 3D shuffling. In the original solution [11], assembly segments are axially connected with upper and lower connecting grapplers to form a full-length assembly, while the segment at the bottom of the core is connected to a shielding and flow orificing block that is designed to remain in a fixed location in the reactor for the lifetime of the core. This design was later carefully evaluated and modified especially for the connecting mechanism to ensure the core stability under all operating conditions and the reliability when moving fuel assembles in the sodium coolant.

Assembly segments are composed of conventional rod-type fuel. In the updated fuel segment design, a nesting tapered conic interface is proposed for the segment-segment interface, as can be seen in Figure 2. The top cap (blue) has a protruding hexagonal cone, 
and the bottom cap (green) has a re-entrant hexagonal cone. The generous tapered hexagonal cone provides a self-centering zone that is larger than the resolution limits of the refueling machine, ensuring consistently robust fuel segment movements. Adequate passages are provided on the conic surface for coolant flow.

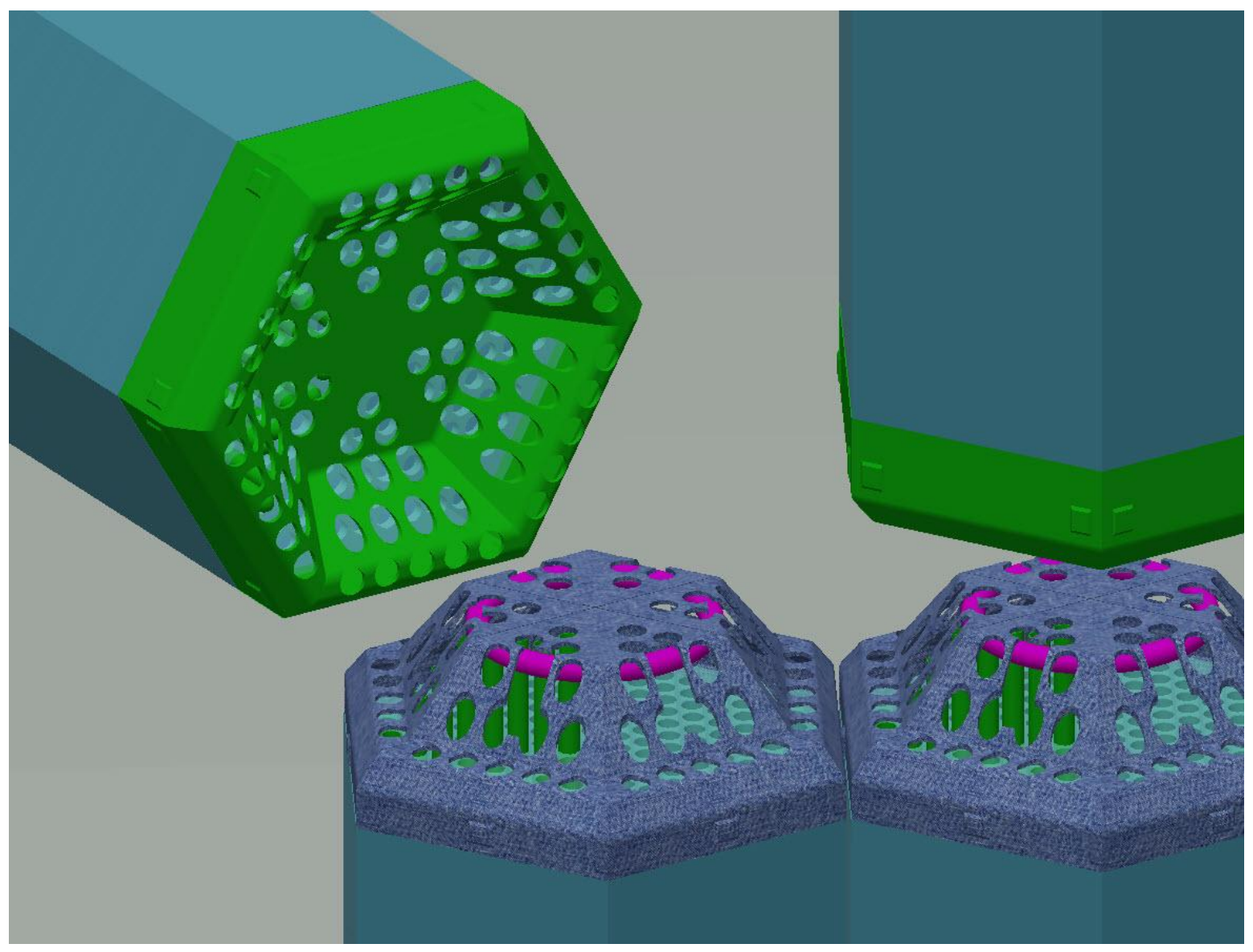

Figure 2 Top and bottom cap of the proposed fuel segment design for 3D fuel shuffling.

Centering buttons on the side of the top and bottom cap provide consistent lateral positioning of the assembly segment in the core and maintain consistent gaps between segments, as shown in Figure 3. Two buttons are provided at the bottom of the segment in order to maintain rotational registry with the core grid, while a single button at the top is adequate to maintain the position of the top of the segment. This arrangement minimizes the dragging of one segment against its neighbors when being inserted or removed. These centering buttons also provide a measure of tolerance for bowing or twisting of fuel assemblies over their service life. 


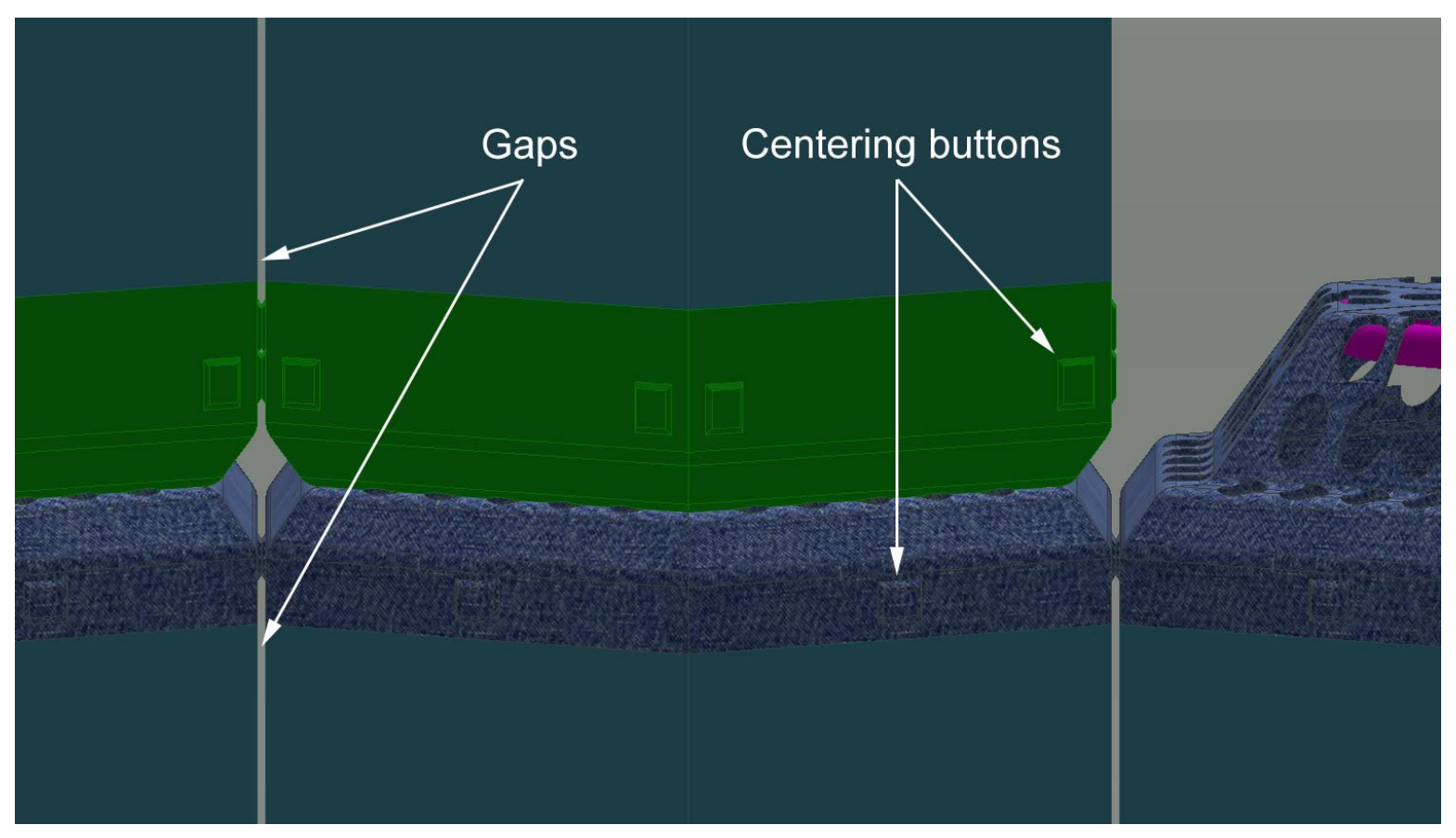

Figure 3 Stacked fuel assembly segments with demonstration of centering buttons at the top and bottom of the segment and the gaps between segments.

Figure 4 demonstrates the design of the fuel handling gripper with 3 jaws, which is positioned at the end of the refueling mast. A robust reinforcing ring is placed in the top of the fuel segment to distribute gripper forces and provide adequate wear surfaces for the life of the segment. A central rod actuator can actuate 3 jaws equally. During the refueling process, the refueling mast is positioned over the assembly segment and extended downwards to reach the segment. The segment is then attached with the handling gripper and lifted up. The gripper is smaller than the footprint of a segment, thus allowing it to reach a fuel segment on the lowest course without removing neighboring segments. 


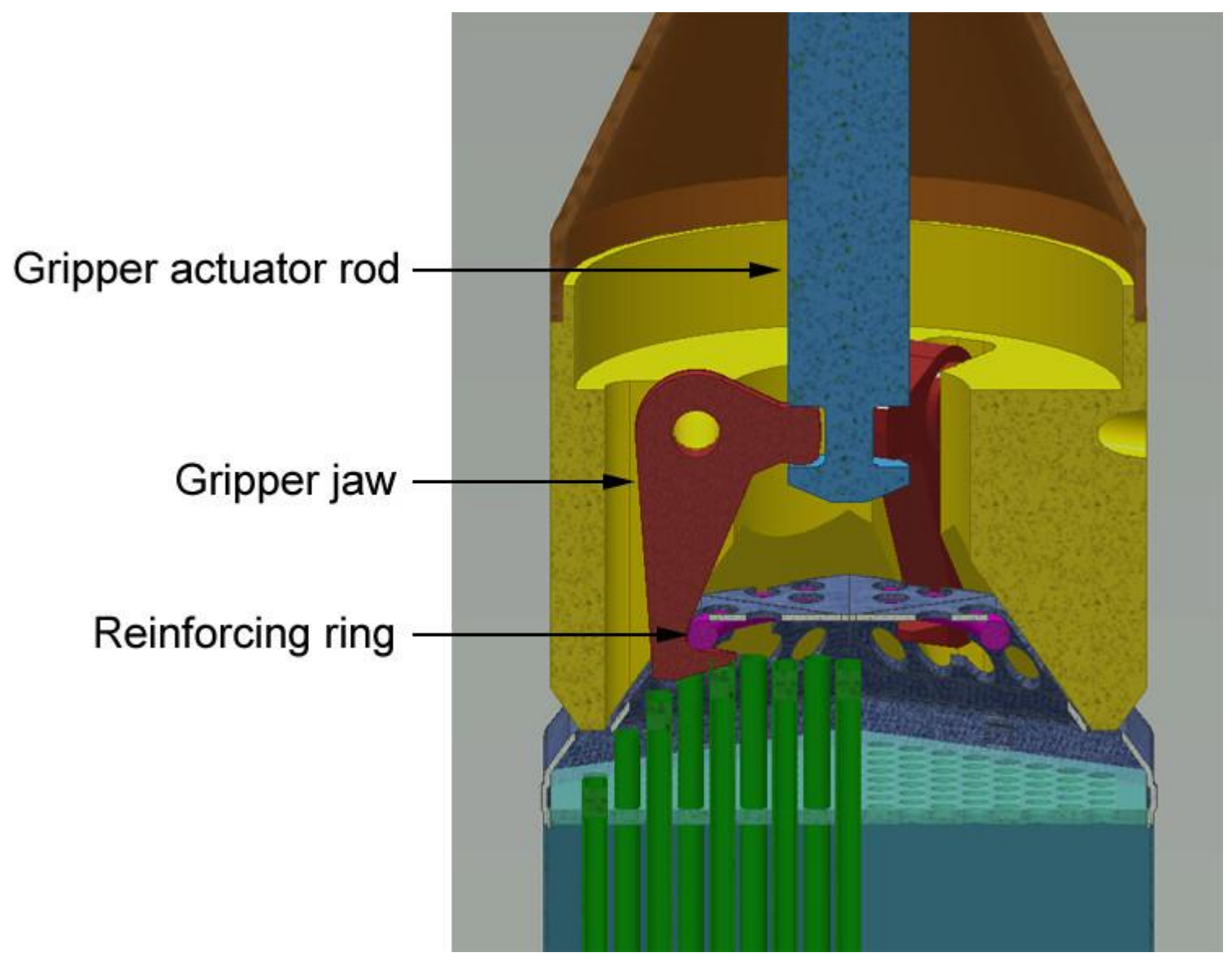

Figure 4 Section view of the fuel gripper mechanism.

The full-length fuel assembly of the first design of 3D shuffled core investigated in this study, named as Design I, is made of four $77 \mathrm{~cm}$ long sub-assemblies making a $301 \mathrm{~cm}$ active core height. This core has three $7 \mathrm{~cm}$ thick fuel-free layers at the top of each of the three lower sub-assemblies due to the design of the sub-assembly fuel rods illustrated in Figure 5. The effective fuel volume fraction of the resulting core is lower than the $2 \mathrm{D}$ shuffled core. The total power of the Design I core with segmented fuel assemblies is the same as of the $2 \mathrm{D}$ reference core.

All the fuel rods are assumed to be vented and allow for continuous release of gaseous fission products through a thin porous filter followed by small openings in the upper end cap as illustrated in Figure 5. In order to minimize the fuel-free volume at the top of the rod, sodium bonding is eliminated. Instead, the metallic fuel is annular and mechanically bonded to a $30 \mu \mathrm{m}$ vanadium liner [22] [23], which acts as a diffusion barrier 
to avoid fuel/cladding chemical interaction. The fuel swelling with burnup is accommodated by the central gap. The mechanical bonding to the cladding restrains the fuel axial swelling thus enabling to minimize the length of the fuel-free section at the top of the fuel rod.

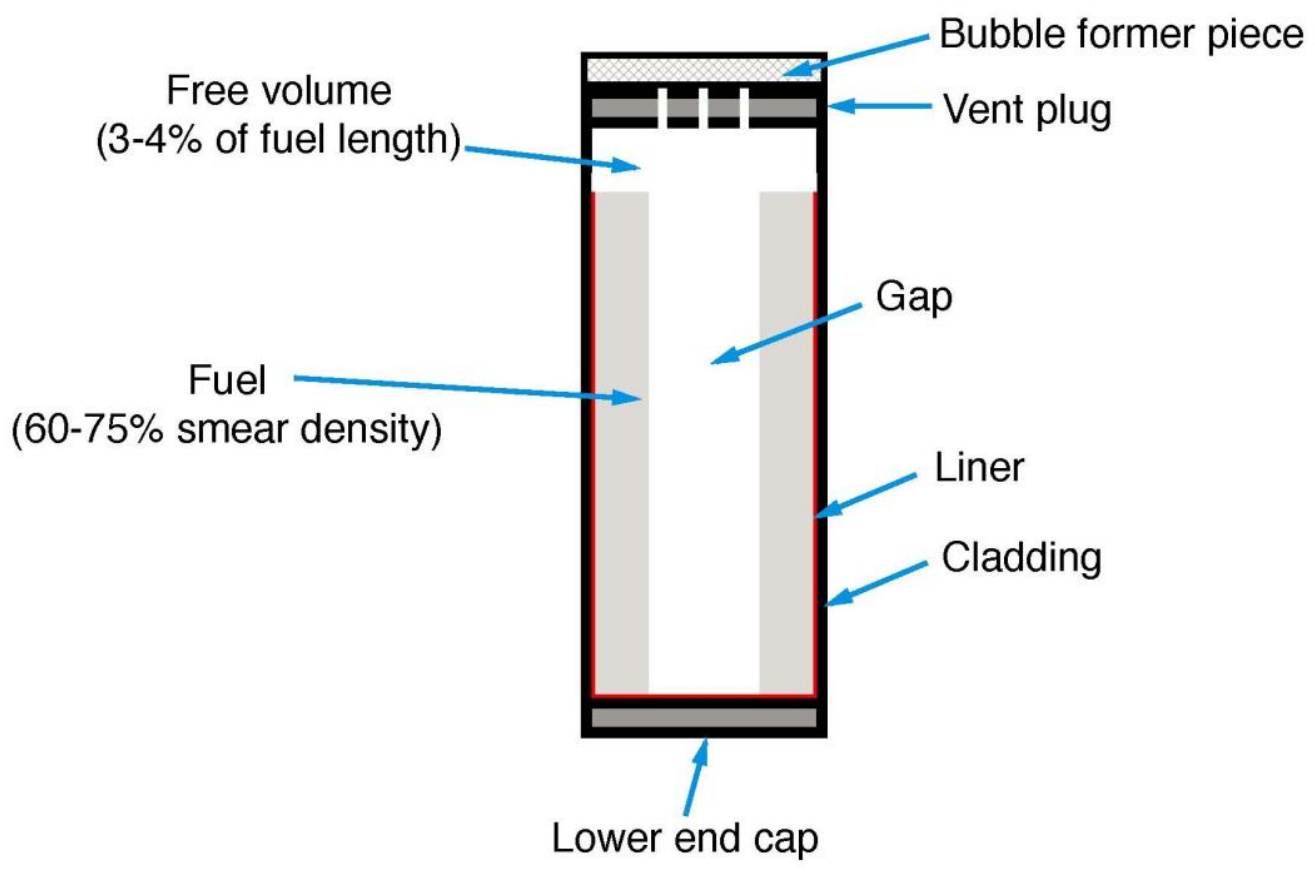

Figure 5 Axially segmented fuel rod design for 3D fuel shuffling.

\subsection{Core design methodology}

\subsubsection{Neutronics model}

The core characteristics compared in this study pertain to the critical equilibrium cycle. The search for the equilibrium cycle was performed using the DIF3D/REBUS-3 codes [24] [25] which are part of the Argonne Reactor Computation (ARC) system from the Argonne National Laboratory (ANL). The finite difference diffusion method was employed in the flux and eigenvalue solver DIF3D as it is the only available option for R-Z geometry. The variable mesh structure can be defined in both radial and axial direction provide a higher resolution of the results, including flux and power etc. The fuel shuffling was modelled explicitly on a fuel batch basis in REBUS-3 calculations. For a given core geometry and 
constituents volume fraction, the design variables are the shuffling pattern and cycle length.

Burnup region-dependent 33-group cross section sets were generated from the ENDF/B-VII.0 data library using the ETOE-2/MC2-3/TWODANT sequence of codes of the ARC package. [26] [27] Specifically, the MC2-3 code first calculates 0-dimensional (0D) neutron spectra and condenses point-wise cross sections prepared by ETOE-2 into an ultrafine group structure ( 2000 groups). For non-multiplying regions such as reflectors and shield, leaking spectra from the fueled region is used for the condensation. Then, a 2-D ultrafine group transport calculation is conducted by TWODANT to take into account realistic leakage and the calculated spectra are fed back to MC2-3 for the final cross section condensation. It was found in previous studies that in order to accurately account for spectral variation in the $\mathrm{B} \& \mathrm{~B}$ core, the best approach is to use burnup and location dependent group constants for the core simulation. [28] However, it is impossible to generate cross sections without knowing the zone-wise equilibrium composition beforehand. It is also difficult to assign cross sections to burnup zones while performing fuel shuffling in REBUS-3. Therefore, the preliminary core calculation was carried out using a cross section set generated for the fuel composition pertaining to intermediate burnup ( 10\% FIMA). This approximation is acceptable for the initial exploration of the effects to be expected from the newly proposed B\&B core design and fuel management.

An external module has been developed to post-process REBUS-3 simulation results and produce key performance characteristics for the equilibrium core such as the zone-wise fuel burnup, infinite multiplication factor, power, and leakage. In particular, the radiation damage accumulated by HT-9 cladding is evaluated by folding cell averaged multi-group flux from REBUS-3 results with the isotopic neutron dpa cross sections. Based on the widely used Norgett-Robinson-Torrens (NRT) model [29], the isotopic dpa cross section is given by the following formula:

$$
\sigma_{\mathrm{DPA}}=\kappa \frac{\sigma_{\mathrm{d}}}{2 \mathrm{E}_{\mathrm{d}}}
$$

where $\sigma_{\mathrm{d}}$ is the damage cross section, which is included in the standard nuclear data in $\mathrm{ENDF} / \mathrm{B}$ format $(\mathrm{MT}=444$ on the PENDF tape) and is available in MCNP libraries for 
most nuclides below $20 \mathrm{MeV}$. In this study, $\sigma_{\mathrm{d}}$ is collapsed into ANL 33-group structure using the same neutron spectrum as in the cross section preparation as described above. $\kappa$ is the displacement efficiency compensating for forward scattering and is usually set to be 0.8. $\mathrm{E}_{\mathrm{d}}$, known as the displacement energy, is the minimum energy required to create a stable interstice and vacancy pair (Frankel pair). A constant value is used for each element in the compound, which is available in the ANL computer code SPECOMP [30]. The dpa cross section of compound materials $\bar{\sigma}_{\mathrm{dpa}}$ takes the form of a weighted average of isotopicwise values, calculated by Eq. (1). The accumulated dpa of HT-9 cladding over the equilibrium cycle is obtained by

$$
R=\sum_{j=1}^{4}\left(\sum_{g=1}^{33} \bar{\sigma}_{d p a, g} \phi_{g, t}\right) \Delta T_{j}
$$

where $\phi_{g, t}$ is the burnup zone averaged neutron flux of group g during burnup step $\mathrm{j}$, and $\Delta \mathrm{T}_{\mathrm{j}}$ is the corresponding burnup step interval. In REBUS-3, the maximum allowable number of burnup steps in the equilibrium cycle is 4 .

In previous studies, [5] the capability of the simplified DIF3D/REBUS-3 model for determining equilibrium composition of $\mathrm{B} \& \mathrm{~B}$ cores has been verified by comparing against a continuous energy Monte Carlo (MC) code Serpent. [31] Both deterministic and MC calculations used the ENDF/B-VII.0 cross section library and assumed uniformity of temperature distribution for fuel/clad $(800 \mathrm{~K})$ and coolant $(600 \mathrm{~K})$ in the active core to have consistency between the two models. They differ, however, in the depletion calculations whereas Serpent uses a detailed burnup chain, the REBUS-3 calculations use a pre-stored plutonium-uranium burnup chain to simplify the input preparation in two ways. First, it does not include all the heavy metal nuclides prepared in the cross section library. Second, the effect of fission products was accounted for using lumped fission product (LFP) cross sections for 4 different fissionable isotopes that were created from cross sections of 137 individual fission products using fission yields for ${ }^{235} \mathrm{U},{ }^{238} \mathrm{U},{ }^{239} \mathrm{Pu}$, and ${ }^{241} \mathrm{Pu}$. It was found [5] that the relative difference of the core characteristics such as cycle length, discharge burnup, reactivity swing, and power peaking factor, is within $4 \%$, indicating that the deterministic approach is adequate for quantifying the relative difference in the 
performance of $\mathrm{B} \& \mathrm{~B}$ cores designed using $3 \mathrm{D}$ versus $2 \mathrm{D}$ fuel shuffling. The computational time for an equilibrium cycle search using REBUS-3 is $\sim 12$ min on the UNIX cluster at $\mathrm{UCB}$, which is a significant reduction when compared with $23 \mathrm{hr}$ using Serpent.

\subsubsection{Coupled neutronics/thermal-hydraulics approach}

The abovementioned standalone neutronics study of the equilibrium performance of the $\mathrm{B} \& \mathrm{~B}$ core assumes that the core can operate at the designed power level without violating any thermal-hydraulics constraints. However, the peak assembly power depends on the radial power distribution which depends on the fuel shuffling scheme. Therefore, thermalhydraulics calculations are incorporated into the core optimization process through coupling with neutronics calculations using the ADOPT code [32]. ADOPT aims to automatically search for the optimal fuel assembly design that maximizes the fuel volume fraction while adhering to set constraints for all component temperatures, pressure drop, coolant velocity and structural integrity limits, subjected to a specified peak assembly power level. The coupling scheme used to converge on thermal-hydraulic and neutronics solutions for critical equilibrium cycle B\&B cores is given in Figure 6. A separate module PyRebus, was developed to prepare the input files, control data exchange, and check the convergence of the iterative process. For a given core specification (defined by geometry, material, SP, etc.), the process starts with REBUS by searching for the equilibrium critical cycle and calculating its performance parameters. Then, the power distribution is sent to the ADOPT model, which has the identical core specification as in REBUS, to generate the volume fraction of all constituents that will enable the peak power assembly to meet all the design constraints. If different from the previous iteration, this information is fed back to REBUS to repeat the search for equilibrium core until a converged critical core design has been found. The fuel volume fraction and the maximum cycle radial power peaking factor require 4-5 iterations to converge to an error less than $2 \%$. 


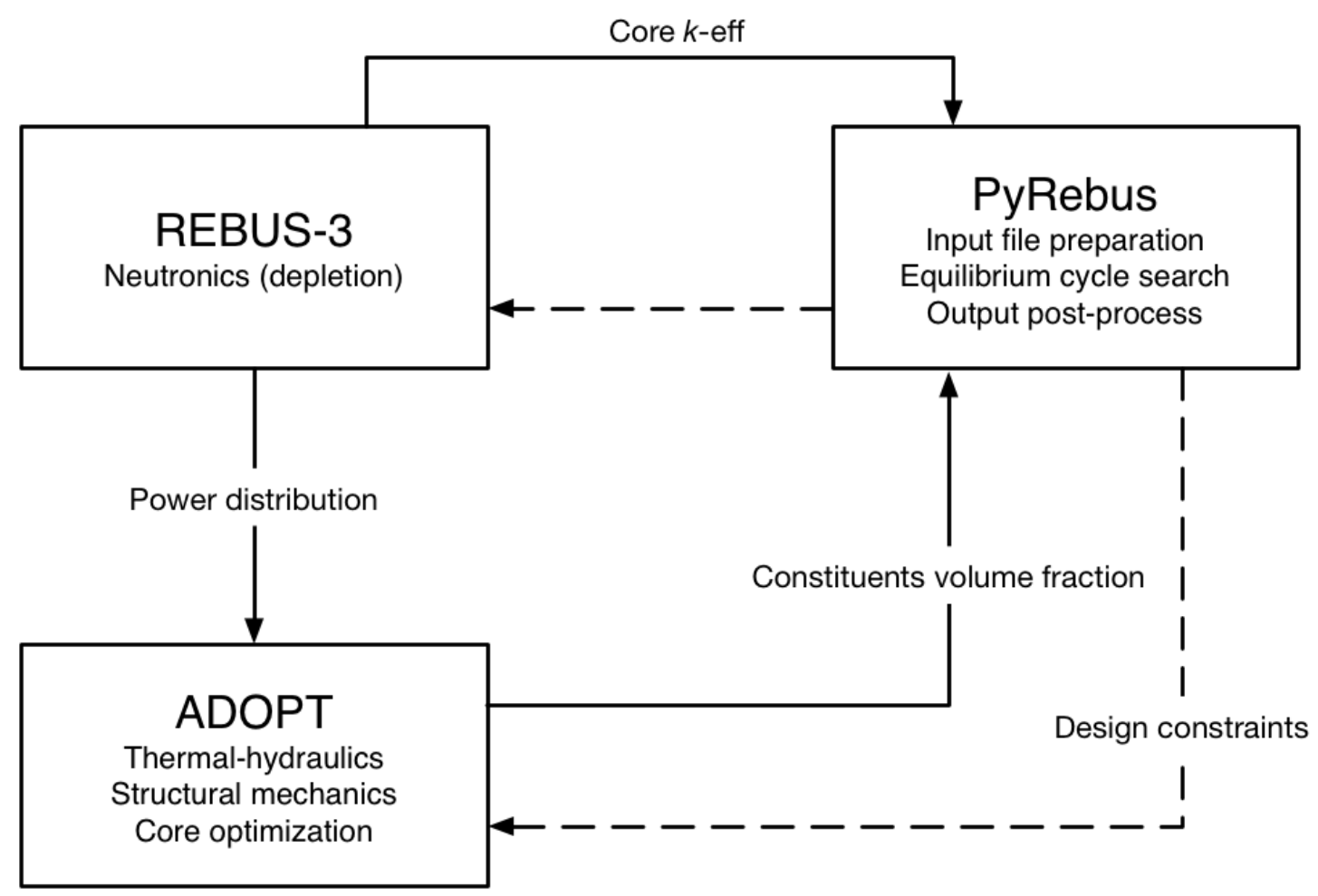

Figure 6 Coupled neutronics-TH calculation scheme for equilibrium B\&B core search.

The thermal-hydraulics constraints accounted for in this study are:

(1) maximum core pressure drop across core: $0.9 \mathrm{MPa},[11]$

(2) maximum sodium velocity across the core: $12 \mathrm{~m} / \mathrm{s},[33]$

(3) maximum fuel-cladding interface temperature: $650{ }^{\circ} \mathrm{C},[34]$ and

(4) maximum peak fuel temperature: $1000{ }^{\circ} \mathrm{C}$. [35]

\section{Shuffling Pattern Optimization Using Simulated Annealing Method}

\subsection{Simulated Annealing Method}

Simulated Annealing (SA) is a stochastic optimization technique motivated by an analogy to annealing in metallurgy, which involves repeatedly heating and cooling of a material to increase the crystal size and remove defects so as to alter its physical properties. The principal fundamental of SA was first introduced by Metropolis [36] as a tool of finding equilibrium configuration of a system of particles at a given temperature. Kirkpatrick et al 
[37] later proposed and applied it to combinatorial optimization problems, in which a family of candidate solutions to minimize the objective function is generated following a Markov chain sampling. Its major advantage over other methods is an ability to avoid being trapped at local minima, because the random search not only accepts changes that improve the solution performance but also some changes that worsen it.

In the general implementation of the SA method [38], a control parameter $T$ is introduced for system temperature, and the energy difference between the two states of the material is replaced by the difference between the current objective function value $\mathrm{F}\left(\mathrm{X}_{\mathrm{i}}\right)$ and the proposed objective function value $\mathrm{F}\left(\mathrm{X}_{\mathrm{j}}\right)$, with $X$ denoting the solution to the optimization problem. The algorithm begins with an initial guess at the optimal solution and then seeks successively improved solutions through a continuing examination of randomly generated solutions in the neighborhood of the ever-changing optimum. For a minimization problem, the probability of acceptance for a new solution $F\left(X_{j}\right)$ is given by

$$
\mathrm{p}(\Delta \mathrm{F}, \mathrm{T})=\min \left\{1, \exp \left(-\frac{\mathrm{F}\left(\mathrm{X}_{\mathrm{j}}\right)-\mathrm{F}\left(\mathrm{X}_{\mathrm{i}}\right)}{\mathrm{T}}\right)\right\}
$$

As such, candidates that decrease $F$ are, of course, accepted, while candidates that increase $F$ by $\Delta \mathrm{F}=\mathrm{F}\left(\mathrm{X}_{\mathrm{j}}\right)-\mathrm{F}\left(\mathrm{X}_{\mathrm{i}}\right)$ are accepted as new solutions with the probability calculated in Eq. (3).

The control parameter $T$ usually decreases in a series of discrete steps over time. In principle, the initial temperature must be high enough to allow shuffling to more neighborhood states. The annealing process continues until the temperature reaches the final temperature, or until some other conditions are met. The most widely used temperature decrement strategy is the exponential multiplicative schedule or geometric schedule, where the temperature decrease is achieved by multiplying the initial temperature $\mathrm{T}_{0}$ by a factor that decreases exponentially with respect to the $k$-th simulation cycle:

$$
\mathrm{T}_{\mathrm{k}}=\mathrm{T}_{0} \alpha^{\mathrm{k}}
$$


where $\alpha(0<\alpha<1)$ is called the cooling parameter. The cooling parameter is the significant search controller. If $\alpha$ is too small, then cooling is too fast, and the search quickly terminates near a local optimum. If $\alpha$ is too large, then cooling is slow, and the search degenerates to an expensive enumeration.

While convergence on the global optimum solution is generally not guaranteed, empirical evidence shows that for many problems, the SA algorithm converges on a family of solutions in the neighborhood of the global optimum and overcomes convergence to local optimum solutions. [39]

\subsection{Optimization Model}

\subsubsection{Formulation of objective functions}

The primary objective of the SP optimization is to reduce the peak minimum required radiation damage as much as possible. However, it is desirable to account for other design constraints including:

(1) Reactivity swing during burnup cycle: $\Delta \rho \leq \Delta \rho^{\text {lim }}$

(2) Change of batch power over the cycle: $\Delta \mathrm{P}_{\mathrm{B}} \leq \Delta \mathrm{P}_{\mathrm{B}}^{\lim }$

(3) Radial power peaking factor: $F_{R} \leq F_{B}^{\lim }$

The burnup reactivity swing FBRs are usually designed to have does not exceed $3.5 \%$. A smaller reactivity swing implies a smaller number of required control assemblies or smaller worth of each control assemblies. The former leads to a higher core average fuel volume fraction and therefore a better neutron economy, while the latter can reduce consequences of a transient overpower accident (UTOP). The minimization of the maximum relative change in the batch power will result in maximum core average coolant exit temperature and, hence, highest possible energy conversion efficiency. This is because the radial coolant flow distribution must be designed, via orificing, for the peak-power conditions and cannot be adjusted over the cycle. Minimization of the radial peaking factor results in minimization of the peak assembly power and maximization of the fuel volume fraction and, hence, of the neutron economy. 
These constraints can be handled in SA as "hard" limits, meaning that any solution that violates them is rejected. For an optimization viewpoint, the disadvantage of this approach is that trapping in local minima can occur, thus preventing an optimal SP from being found. [17] An alternative is to define an augmented objective function, in which the main objective function is augmented by the penalty terms reflecting the extent of violation of the active constraints:

$$
\overline{\mathrm{F}}=\gamma \mathrm{R}^{*}+\sum_{\mathrm{i}=1}^{\mathrm{I}} \lambda_{\mathrm{i}} \Omega_{\mathrm{i}}
$$

where the first term on the right side of Eq. (5) is the main objective function corresponding to the evaluation of peak radiation damage, and each penalty term in the summation represents the contribution of one of the constraint related objectives to the augmented objective function. The violation functions $\Omega$, taking the forms given in Table 2 , are the relative differences of current value of the parameter from the pre-defined design constraints, of which the values in the $3^{\text {rd }}$ column of the same table were adopted in this study. The impact factor $\lambda$ are introduced to adjust the importance of each objective; for example, in the case where reactivity swing minimization takes the priority in SP optimization, all that must be done for the objective function transition is to increase the impact factor associated to $\Omega_{1} \cdot \gamma$ is a multiplication constant used to adjust $R^{*}$ to the same order of magnitude of the penalty terms in Eq. (5); a value of 0.01 is used in this study.

Table 2 Elements and constraints of augmented objective function

\begin{tabular}{|l|l|l|}
\hline Description & Violation function & Constraint \\
\hline Reactivity swing during burnup cycle & $\Omega_{1}(\Delta \rho)=\frac{\Delta \rho}{\rho^{\lim }}-1$ & $\Delta \rho^{\lim }=7.0$ \\
\hline Max change of batch power & $\Omega_{2}\left(\Delta \mathrm{P}_{\mathrm{b}}\right)=\frac{\Delta \mathrm{P}_{\mathrm{b}}}{\Delta \mathrm{P}_{\mathrm{b}}^{\lim }}-1$ & $\Delta \mathrm{P}_{\mathrm{B}}^{\lim }=\frac{\mathrm{P}_{\mathrm{th}}}{\mathrm{N}_{\mathrm{b}}}$ \\
\hline Radial power peaking factor & $\Omega_{3}\left(\mathrm{~F}_{\mathrm{R}}\right)=\frac{\mathrm{F}_{\mathrm{R}}}{\mathrm{F}_{\mathrm{R}}^{\lim }}-1$ & $\mathrm{~F}_{\mathrm{R}}^{\lim }=2.5$ \\
\hline
\end{tabular}

${ }^{\ddagger} \mathrm{P}_{\text {th }}$ refers to the core thermal power; $\mathrm{N}_{\mathrm{b}}$ denotes the number of radial fuel batches in the core. 


\subsubsection{Solution update and cooling scheme}

The variable of the optimization problems considered in this work is the SP, which can be visualized as a 2D array of burnup zones. Given as an example of SP map in Figure 7, four layers of zones indicate that a fuel assembly is constituted of four axially stacked segments, and the radial zones correspond to fuel batches. The lower left corner on the map is the center of the core lower boundary. In the 3D shuffling, the content of one sub-assembly or burnup zone can be relocated to any other zone on the SP map at the refueling stage before discharged from the core. The tracking of the fuel content creates a fuel management path, which represents a unique shuffling sequence of this sub-assembly. In a 12-batch core using the current assembly design, there exist four independent fuel paths, each consisting of 12 burnup stages. In the 2D shuffling, the SP map is reduced to 1D array of 12 burnup zones, because the fuel assembly is only shuffled in radial direction.

The mechanism for generating a candidate SP from the current solution is based on binary fuel exchange, which involves the exchange of burnup cycle numbers of two randomly selected fuel zones from the SP map. In the 3D shuffled case, an additional exchange is required for another two zones, whose positions are axially symmetric with those in the first operation, so that the symmetry of the SP can be preserved. The normal and dashed lines in Figure 7 demonstrate these two executive operations in a SP with four axial assembly segments (as in Design I core). This type of SP is later referred to as "unconstrained" SP, because it imposes no restrictions on the choice of four sub-assemblies for reconstituting new fuel assemblies. In a 2D shuffled case, the exchange is performed only once for two randomly selected batches, or equivalently two columns in the 3D shuffling map. The binary exchange update scheme is designed in such a way that the perturbation to the accepted SP is small enough to ensure the desirable attributes can be carried forward. 


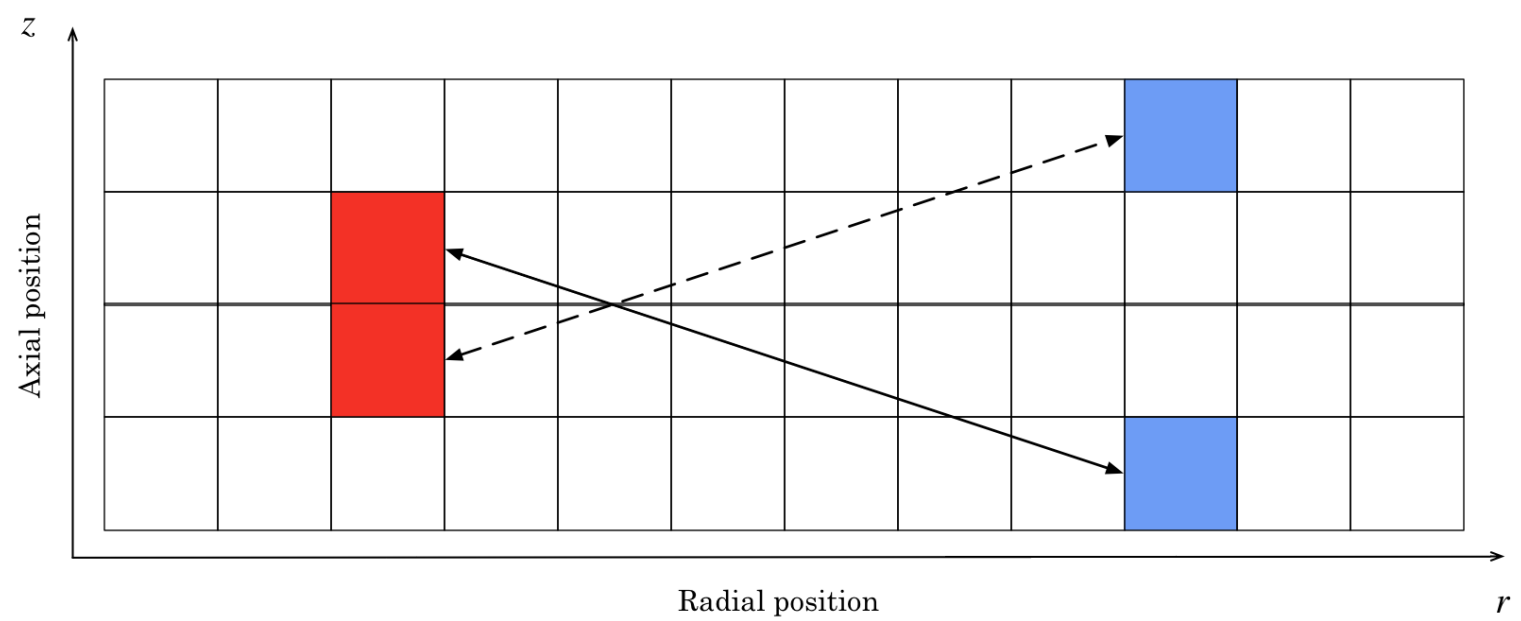

Figure 7 Shuffling pattern update scheme: binary fuel exchange.

For the purpose of expediting the optimization, the randomly generated SP goes through a screening process for additional restrictions before the performance evaluation. For example, the fresh fuel loading is restricted to the core radially outermost batch. This is primarily to minimize the radial leakage probability, but can also significantly reduce the search space of the optimization process. In 3D shuffled case, discharging fuel from axial boundary zones is avoided because previous studies show that the loading of high reactivity fuel in boundary zones introduces strong axial leakage and imposes detrimental impact on the neutron economy.

As shown in Eq. (3), the probability of accepting worse SPs is also reduced with the control parameter $T$ as the optimization proceeds. The value of $T$ has no physical meaning and its scale is highly dependent on the problem under consideration such as the initial guess of the SP. The determination of the initial value of $T$ is then transferred to the determination of the initial acceptance probability, because the latter defines the optimization process in a more direct way and has little problem dependence, as pointed out in Ref. [18] Once the initial probability threshold $\mathrm{P}_{0}$ is input by the user, several trial-anderror runs are conducted to estimate the average change in the objective function outcome $\overline{\Delta F}$. Based on Eq. (3), the value of $\mathrm{T}_{0}$ can be determined as 


$$
\mathrm{T}_{0}=-\frac{\overline{\Delta \mathrm{F}}}{\ln \mathrm{P}_{0}}
$$

A value of $P_{0}$ usually selected is $\approx 8.2$ as it was found to ensure early acceptance of solutions between local minima. The selection of the cooling parameter value $\alpha$ is usually arrived at based on the experience, but typically it is between 0.80 and 0.99. [39] A number at the higher end of this range is preferred as the design space for this problem is highly nonlinear. The final value of $T$ can be determined by its initial value, the total number of cooling stages and the cooling parameter $\alpha$.

In summary, the SA optimization proceeds by performing a perturbation to the initial guess of SP, based on a single binary fuel exchange, and calculating the initial probability of acceptance. The SA algorithm then chooses whether or not to preserve or replace the current SP. More binary exchanges are then performed, producing improved evaluations of the objective function at decreasing values of the control parameter $T$ until the maximum number of cooling stages specified by the user is reached. A strategy flowchart of the optimization process is displayed in Figure 8, in which the term "evaluate SP" refers to the estimation of the augmented objective function outcome for a specific SP using REBUS. 


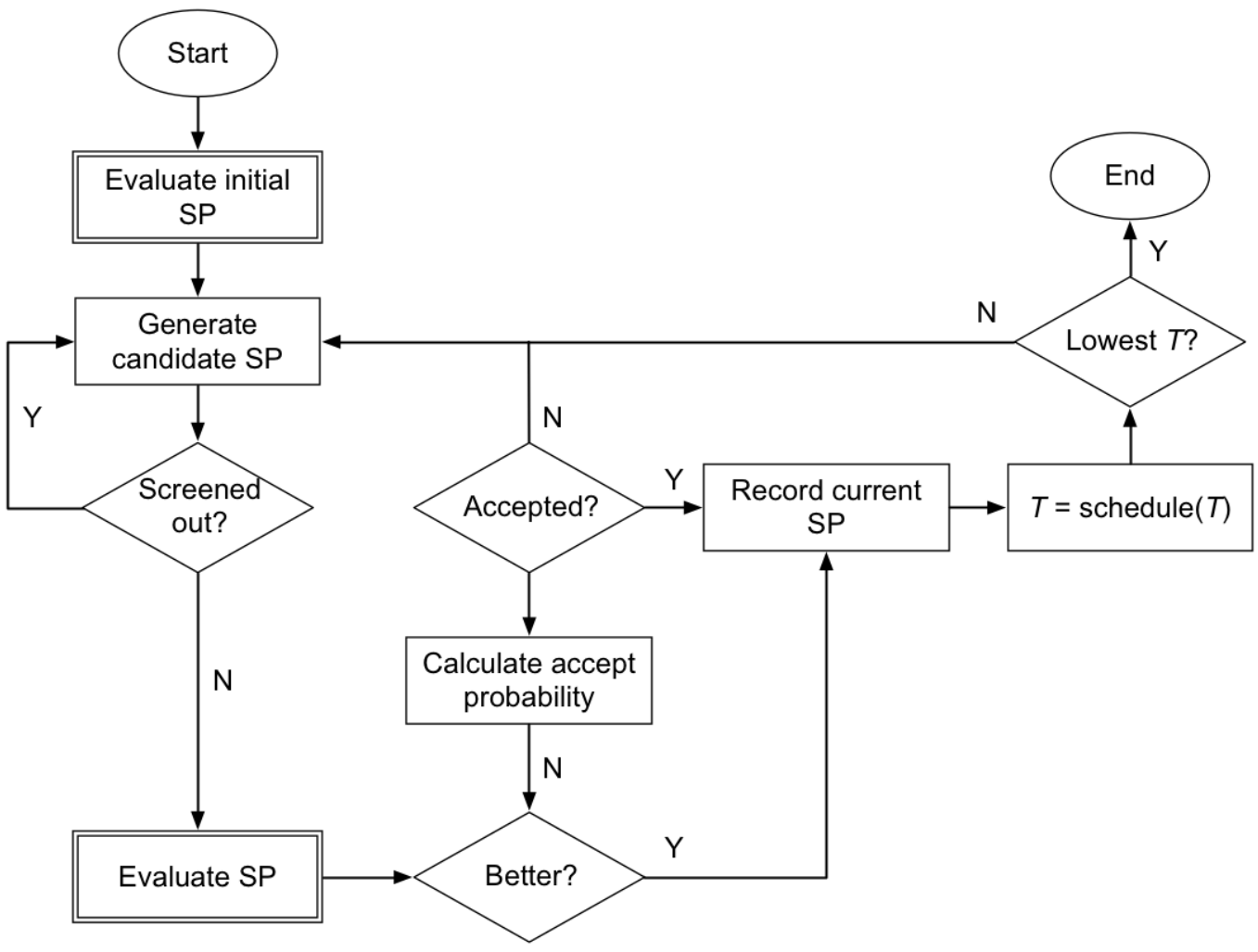

Figure 8 Flow diagram of shuffling pattern optimization using simulated annealing.

\section{Simulation Results and Analyses}

The performance of the SA algorithm was first examined by optimizing the SP for both the 2D shuffled reference core and the 3D shuffled Design I core; both using 12-radial batches. The "out-in" SP was selected as the initial guess, where the fresh fuel is loaded at the outmost radial batch, sequentially shuffled inwards at the end of cycle and finally discharged from the central core batch. The reason for choosing this SP, which inevitably leads to an extreme radial power peaking, rather than using some already optimized SP otherwise as the initial SP is to avoid trapping in the local minima and enable deeper exploration of the new methodology and design space.

In the 2D shuffling, each assembly was subdivided into 8 equal volume axial burnup zones, while in the 3D shuffling each of the four sub-assemblies was subdivided into two burnup zones so that a consistent comparison of core performance can be 
performed for the two cases. The path dependent burnup and radiation damage were calculated based on these eight burnup zones. .

The behavior of the augmented objective function, defined by Eq. (5), as well as of its components, in the 3D shuffled case is displayed in Figure 9 as a function of cooling stage. The radial power peaking factor or the peak assembly power was considered as a thermal-hydraulics constraint and is not included in the neutronics optimization. It was later on taken into account separately in the thermal-hydraulics validations, as described in Section 2.3.2, to adjust the achievable fuel inventory for a selected SP. All other active constraints were considered equally important, so 1.0 was adopted for all impact factors $\lambda$. As a result, the current problem is considered as the multi-objective optimization problem aiming at finding the best SP to have the lowest possible peak radiation damage $(\mathrm{R} *)$, the smallest burnup reactivity swing $(\Delta \rho)$ and the least relative change of batch power $\left(\Delta \mathrm{P}_{\mathrm{B}}\right)$. The initial and final temperatures of this case were determined to be 6.15 and 0.22 , respectively, based on the approach described in Section 3.2.2.

In the first 500 cooling stages in the optimization history, all components of the augmented objective function clearly exhibit a decreasing trend, with larger oscillations at the early stage and smaller towards the end. It implies that the SA algorithm allows a wide exploration of the design space by accepting solutions degrading the core performance, and tightens the acceptance criterion as the simulation proceeds. It could also be seen that penalty terms reached their minima at different rates, and the minimum value of the augmented objective function is found at cooling stage 464. In this case, most of the SPs generated after the 400 simulation cycle are preferred from the neutronics point of view, among which four SPs with low radial power peaking factor were selected for thermalhydraulics evaluation. For each of the SPs, it took no more than five iterations for the REBUS-ADOPT approach to arrive at converged volume fractions and radial power peaking factor, and generate the best 3D SP that can meet all thermal-hydraulics constraints. 


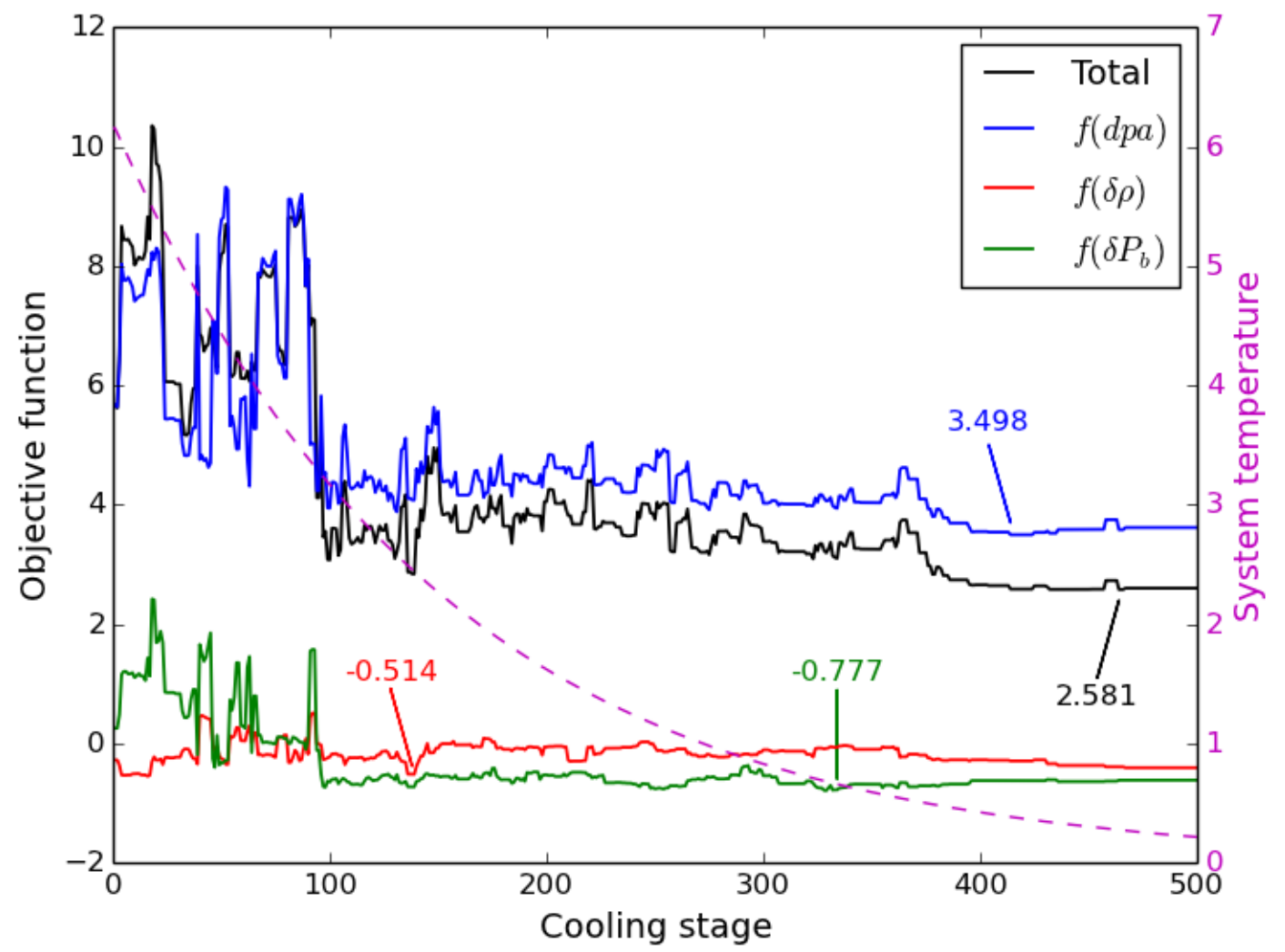

Figure 9 Convergence history of SP optimization with SA algorithm.

The same SP optimization was conducted for the 2D SP, and the actual optimum SP is depicted at the top of Figure 10. The fresh fuel is loaded at the core periphery, then shuffled to the center, before starting to "bounce" between the outer and inner region of the core and finally discharged from the $8^{\text {th }}$ radial location. The optimum 3D SP, as shown in the bottom of Figure 10, uses four independent fuel paths. The colors of the 3D SP distinguish those shuffling paths, while the numbers indicate the burnup cycle of the relocation ( 1 where the fuel is loaded and 12 where the fuel is discharged). It can be seen that the fuel is shuffled to the high reactivity worth regions after the first irradiation cycle and discharged from the core axial center from the $10^{\text {th }}$ and $11^{\text {th }}$ radial positions. 


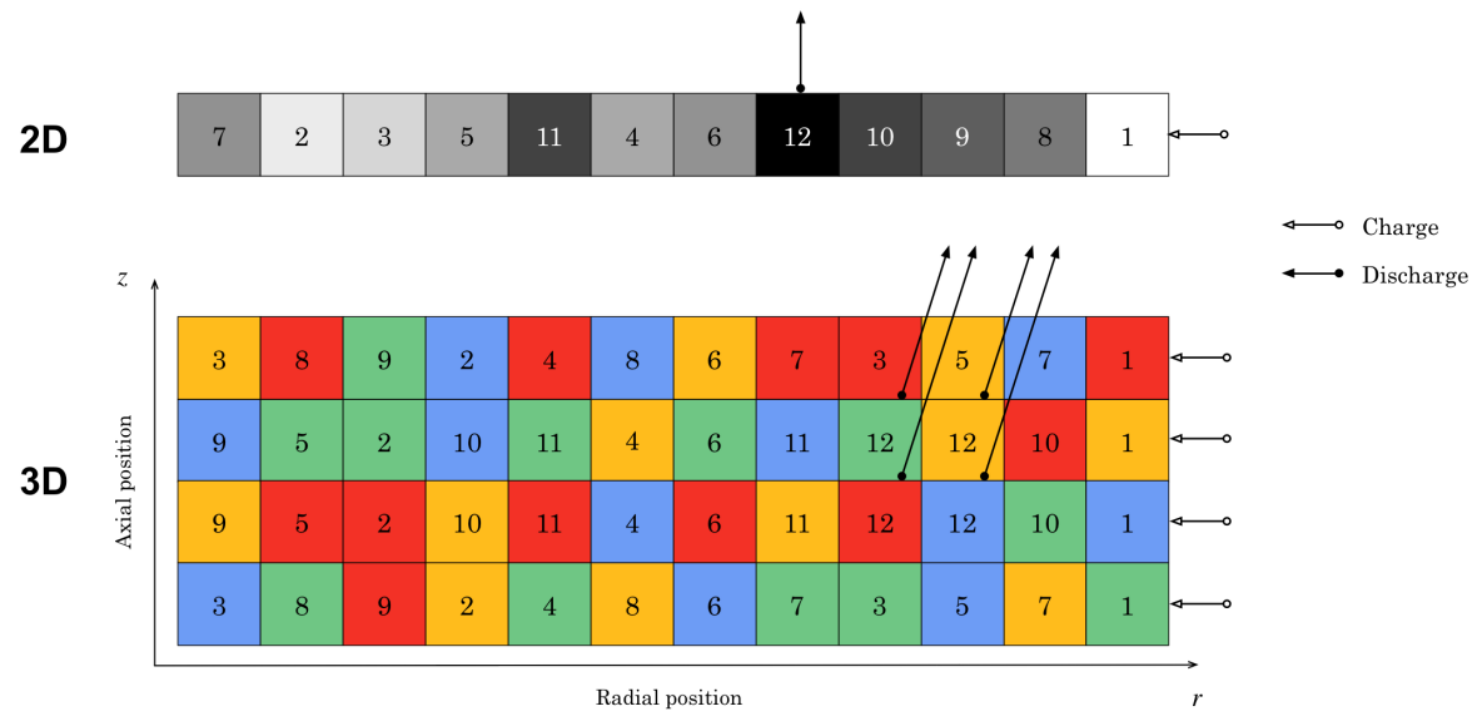

Figure 10 Optimal 2D (top) and 3D (bottom) shuffling pattern for Design I B\&B core.

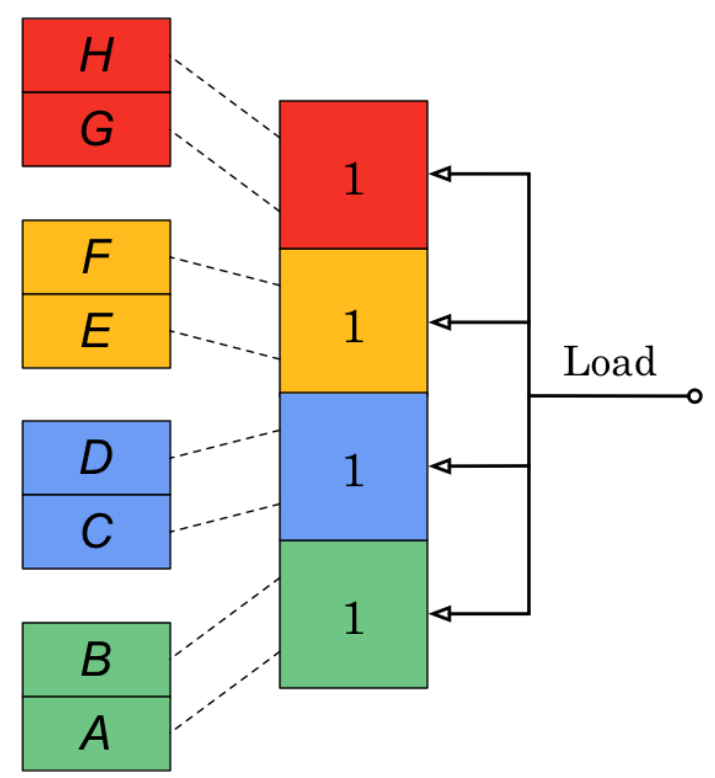

Figure 11 Axial discretization of fuel zones.

Table 3 compares the equilibrium core performance using the optimal 2D and 3D SP described above. The 3D shuffling enables a 34\% reduction of the peak radiation damage - from 534.2 dpa in 2D shuffling case to 351.0 dpa for the 3D case. The equilibrium cycle length was increased from 1083 for 2D to 1566 effective full power days (EFPD) for 3D shuffled systems. The corresponding average discharge burnup increased from $9.91 \%$ to $14.49 \%$ FIMA. This implies an approximately $45 \%$ increase in the fuel 
utilization. If normalized to the same dpa level, the average discharge burnup of the 3D shuffled core is 2.23 times that of the $2 \mathrm{D}$ shuffled core; this corresponds to a relative increase in the fuel utilization of nearly $120 \%$. Although 351 dpa is still beyond the proven radiation damage limit for HT-9 cladding, it is expected that ongoing and future irradiation experiments and new material development will enable to reach this dpa value much sooner and with higher certainty than the $>500$ dpa required for $2 \mathrm{D}$ shuffling cores.

Table 3 Results for Design I B\&B core (3000 MW)

\begin{tabular}{|c|c|c|c|}
\hline \multicolumn{2}{|c|}{ Equilibrium parameter } & 2D shuffled & 3D shuffled \\
\hline \multicolumn{2}{|c|}{ Burn cycle time (EFPD) } & 1083 & 1566 \\
\hline \multicolumn{2}{|c|}{ Burnup reactivity swing $(\% \Delta \mathrm{k} / \mathrm{k})$} & 2.81 & 4.66 \\
\hline \multicolumn{2}{|c|}{ Average discharge BU (\% FIMA) } & 9.91 & 14.49 \\
\hline \multicolumn{2}{|c|}{ Peak discharge BU (\% FIMA) } & 23.62 & 15.69 \\
\hline \multicolumn{2}{|c|}{ Peak radiation damage (dpa) } & 534.2 & 351.0 \\
\hline \multicolumn{2}{|c|}{ Peak fast fluence $\left(\mathrm{n} / \mathrm{cm}^{2}\right)$} & $1.28 \mathrm{E}+24$ & $9.88 \mathrm{E}+23$ \\
\hline \multicolumn{2}{|c|}{ Axial/radial leakage probability (\%) } & $1.00 / 2.67$ & $1.56 / 2.75$ \\
\hline \multicolumn{2}{|c|}{ Axial/radial power peaking factor } & $2.35 / 1.64$ & $2.00 / 1.70$ \\
\hline \multicolumn{2}{|c|}{ Peak batch power change $(\%)$} & 17.07 & 22.14 \\
\hline \multicolumn{2}{|c|}{ Pitch-to-diameter ratio } & 1.065 & 1.070 \\
\hline \multirow{5}{*}{$\begin{array}{l}\text { Core volume } \\
\text { fractions (\%) }\end{array}$} & Fuel & 40.16 & 39.77 \\
\hline & Gap & 13.39 & 13.26 \\
\hline & Cladding+Wire & 12.85 & 12.77 \\
\hline & Duct & 6.59 & 6.57 \\
\hline & Coolant & 27.03 & 27.63 \\
\hline
\end{tabular}

The thermal-hydraulics corrected fuel volume fraction was $40.16 \%$ and $39.77 \%$, corresponding to the fuel pin pitch-to-diameter (P/D) ratio of 1.065 and 1.070, for $2 \mathrm{D}$ and 3D shuffled system, respectively, due to the somewhat higher radial power peaking factor of the 3D shuffled core. The radial and axial power distributions of the 2D and 3D shuffled cores, shown in Figure 12 and Figure 13, are quite similar. The radial power distribution peaks at the $8^{\text {th }}$ radial batch since a large portion of the high burnup and, therefore, high $\mathrm{k}_{\infty}$ fuel is located in radial batches 8 through 10 . Over the cycle the radial power distribution 
tends to shift towards the core center as the fissile contents builds up steeply with burnup at the low burnup fuel that is loaded at the inner region of the core. Due to the axial shuffling of the segmented assemblies, the axial peaking factor was brought down from 2.35 in 2D to 2.00 in $3 \mathrm{D}$ shuffled core. As a result, the leakage probability from the $3 \mathrm{D}$ shuffled core is 17\% higher.
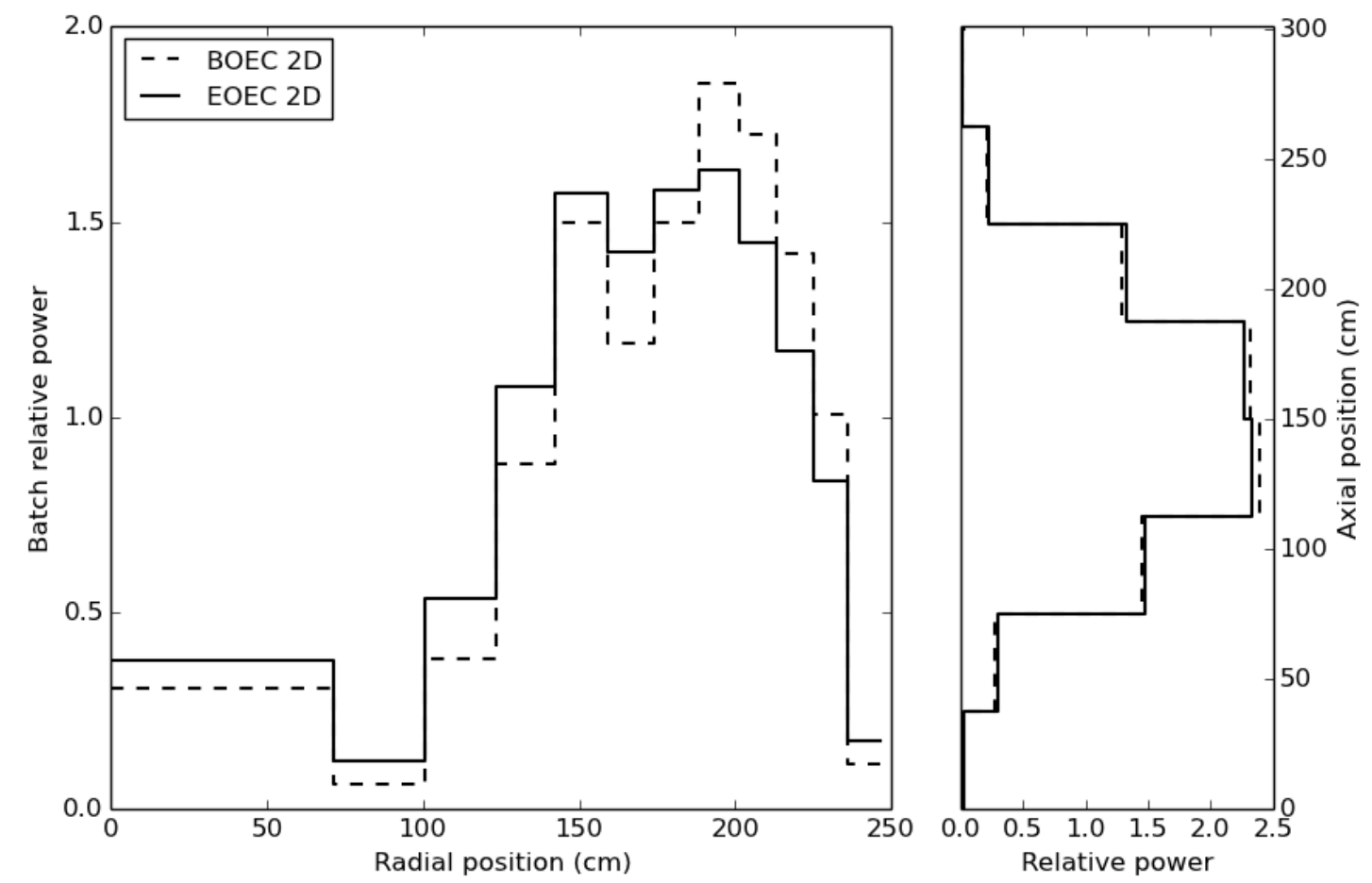

Figure 12 Radial and axial power distribution for 2D shuffled Design I core. 

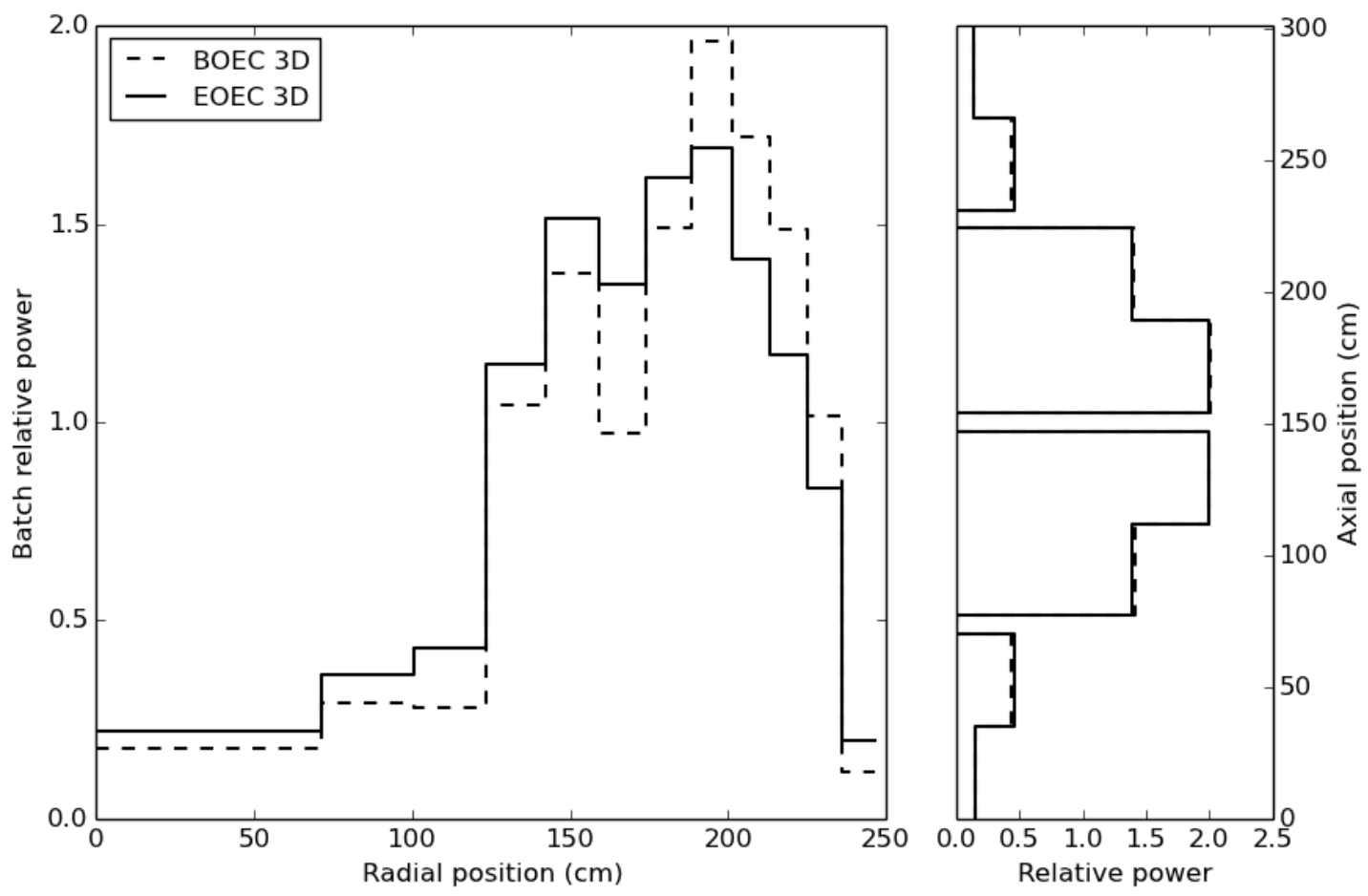

Figure 13 Radial and axial power distribution for 3D shuffled Design I core.

It should be noted that a relatively fine computational mesh has been applied to the finite-difference calculation of the equilibrium core using DIF3D with the mesh size always smaller than $5 \mathrm{~cm}$ everywhere in the active core in both radial and axial direction. This is considered adequate for the fast reactor simulation. The fine-mesh output of power and flux were then averaged within each burnup zone to obtain the corresponding distribution in a coarser discretization, from which the peak and average value of some of the key performance characteristics were interpreted, such as power and radiation damage. Despite the simplified cylindrical geometry, this spatial mesh structure (as seen in Figure 12 and Figure 13) is considered adequate to represent the actual core performance. This is because the $\mathrm{B} \& \mathrm{~B}$ core has to be designed sufficiently large to improve the neutron economy and each fuel batch consists of a large number of assemblies, which leads to many possible ways to reduce the peaking factor in each batch to nearly 1.0 by carefully choosing the new location and rotation for each assembly during fuel shuffling. This is especially the case for 3D shuffling where the axial movement of the fuel segment is realized. However, the development of the explicit assembly-based SP and its optimization were not included in 
the current study and will be pursued when a hexagonal assembly-by-assembly model is available.

The neutron balance analysis described in [40] [41] can be used to estimate the net number of excess neutrons generated by a unit volume of fuel, $N_{\mathrm{ex}}$, as a function of burnup as follows:

$$
\mathrm{N}_{\mathrm{ex}}=\mathrm{N}_{\mathrm{HM}} \int_{0}^{\mathrm{BU}}\left[1-\frac{1}{\mathrm{k}(\mathrm{BU}) \times \mathrm{P}_{\mathrm{NL}} \times \mathrm{P}_{\mathrm{NRC}}}\right] \overline{\mathrm{v}}(\mathrm{BU}) \mathrm{dBU}
$$

In the above, $k(B U)$ refers to the $k_{\infty}$ evolution with burnup in the control volume. Although in practice fuel is shuffled in the reactor core and thus depleted with variable power density during its lifetime, the $k_{\infty}$ evolution curve in the infinite medium with fixed power density can be used to understand its behavior as a function of burnup, as illustrated in Figure 14. It can be seen that $k_{\infty}$ increases rapidly with burnup before it reaches 1.0 and the change slows down in the vicinity of its maximum value.

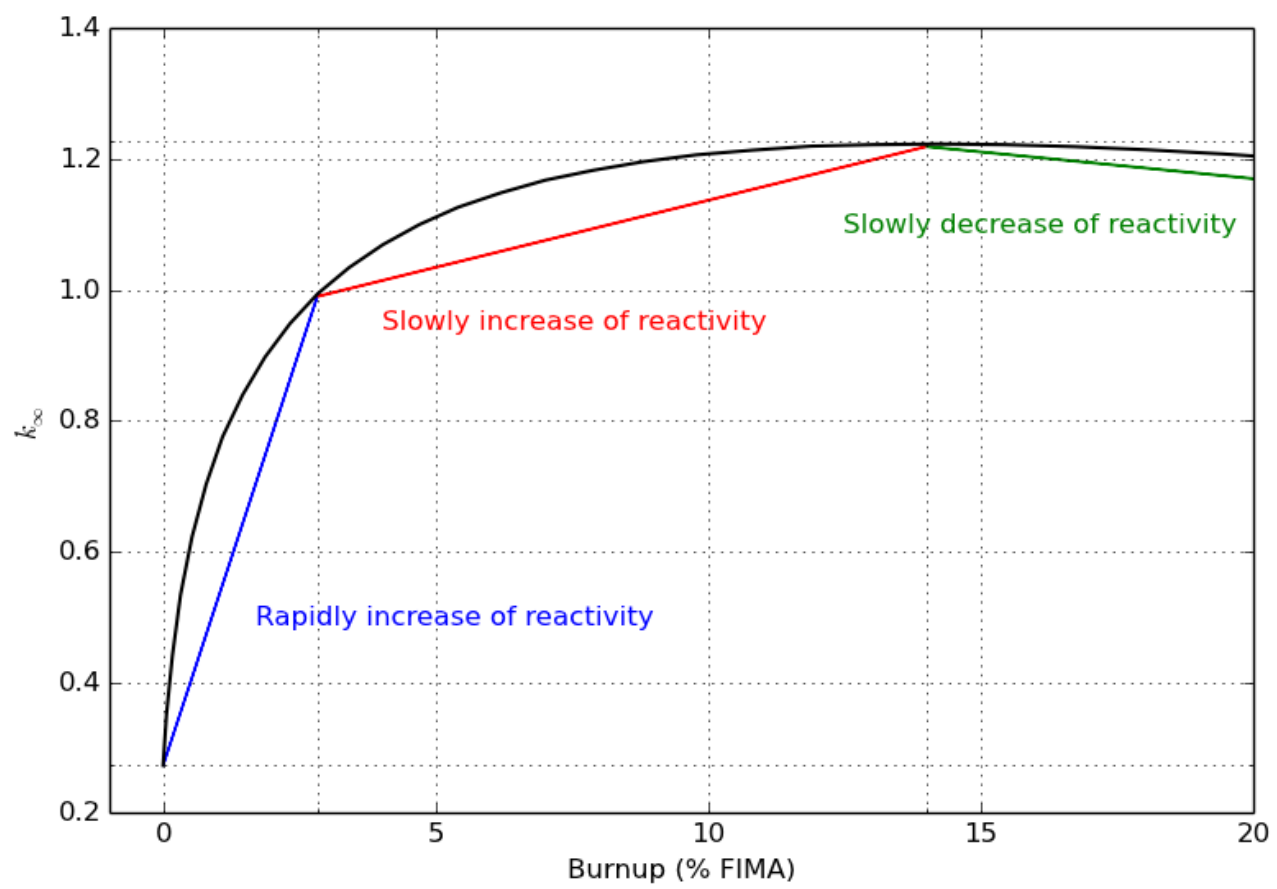

Figure $14 k_{\infty}$ evolution with burnup of metallic DU fuel [11]. 
In Eq. (7), $\mathrm{N}_{\mathrm{HM}}$ is the Heavy Metal (HM) atom density, BU is the burnup expressed in FIMA, $\bar{v}(\mathrm{BU})$ is the average number of neutrons released per fission, $P_{\mathrm{NL}}\left(=1-P_{\mathrm{L}}\right)$ is the non-leakage probability and $P_{\mathrm{NRC}}\left(=1-P_{\mathrm{RC}}\right)$ is the probability that a fission-born neutron will escape capture in the control elements used to compensate for the burnup reactivity swing over the equilibrium cycle. The minimum burnup required for sustaining a $\mathrm{B} \& \mathrm{~B}$ operation is that burnup for which $N_{\mathrm{ex}}=0$.

A neutron balance analysis is carried out for each of the 8 axial equal burnup fuel batches as they traverse the core from loading to discharge. The burnup dependent infinite multiplication factor of each of these fuel batches is calculated as the ratio of neutron production rate to neutron absorption rate. The neutron production from $(n, 2 n)$ and $(n, 3 n)$ reactions is assumed negligible. It is assumed that the neutron loss is constant throughout the cycle and equals to the average of its BOEC and EOEC values. Figure 15 and Figure 16 plot the neutron balance curves of 4 out of the 8 axial fuel burnup batches, also referred to as "fuel paths", for the optimal 2D and 3D shuffled cores following each batch shuffling path as defined in Figures 8 and 9. Because of near axial symmetry, the neutron balance of the other four axial fuel burnup paths is very similar. The turning point of the neutron balance plots from a negative to a positive slope corresponds to $k_{\infty}$ of 1.0; at smaller burnups the fuel is a net neutron consumer-i.e., it absorbs more neutrons than it generates, while at higher burnups the rate of fission neutrons the fuel generates exceeds the rate of neutrons it absorbs. A negative sign in the neutron balance implies that there is a net cumulative neutron loss, whereas a positive sign pertains to burnup over which a net excess of neutrons has been generated by a unit fuel volume. 


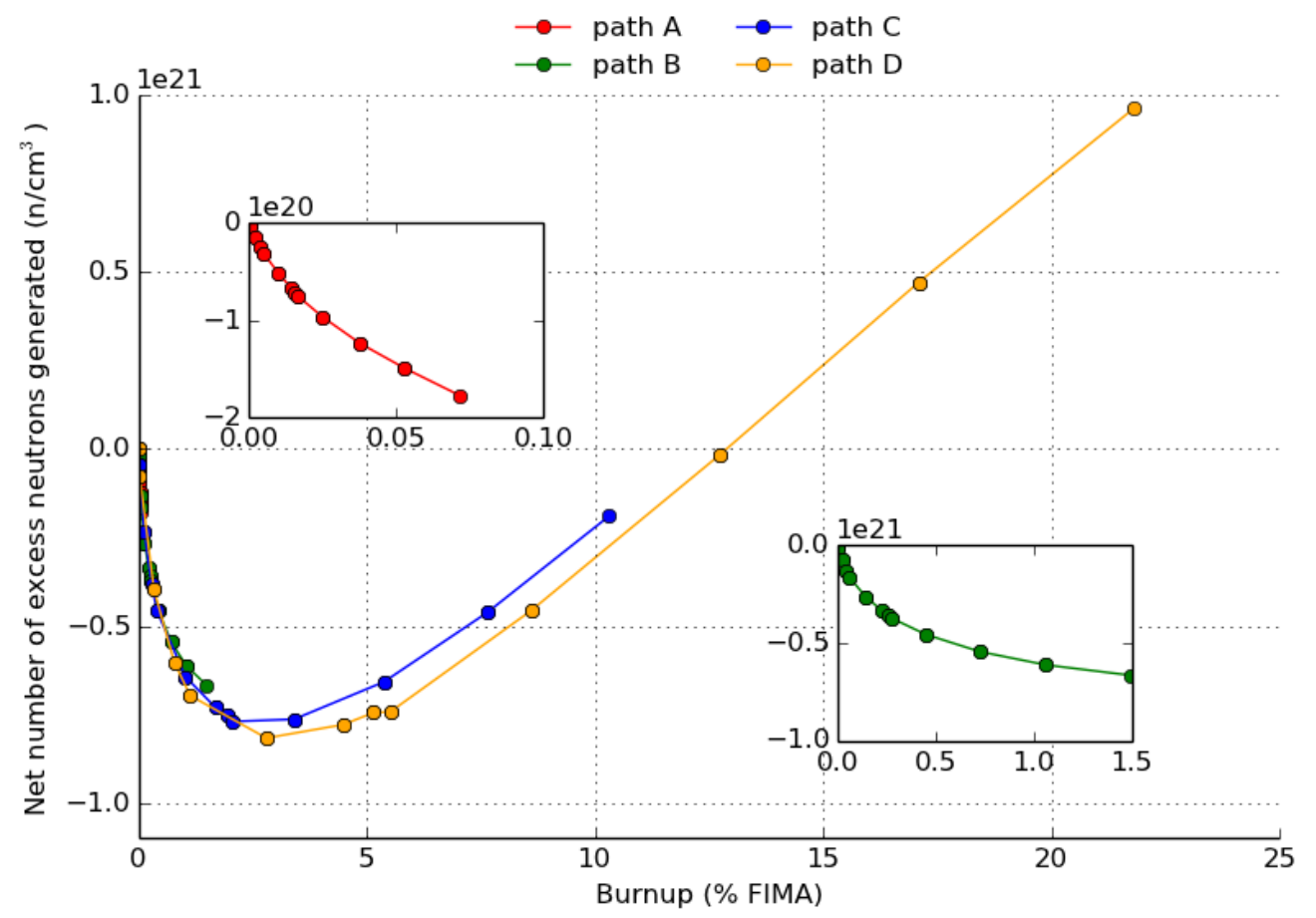

Figure 15 Fuel path dependent neutron balance of 2D shuffling for Design I core.

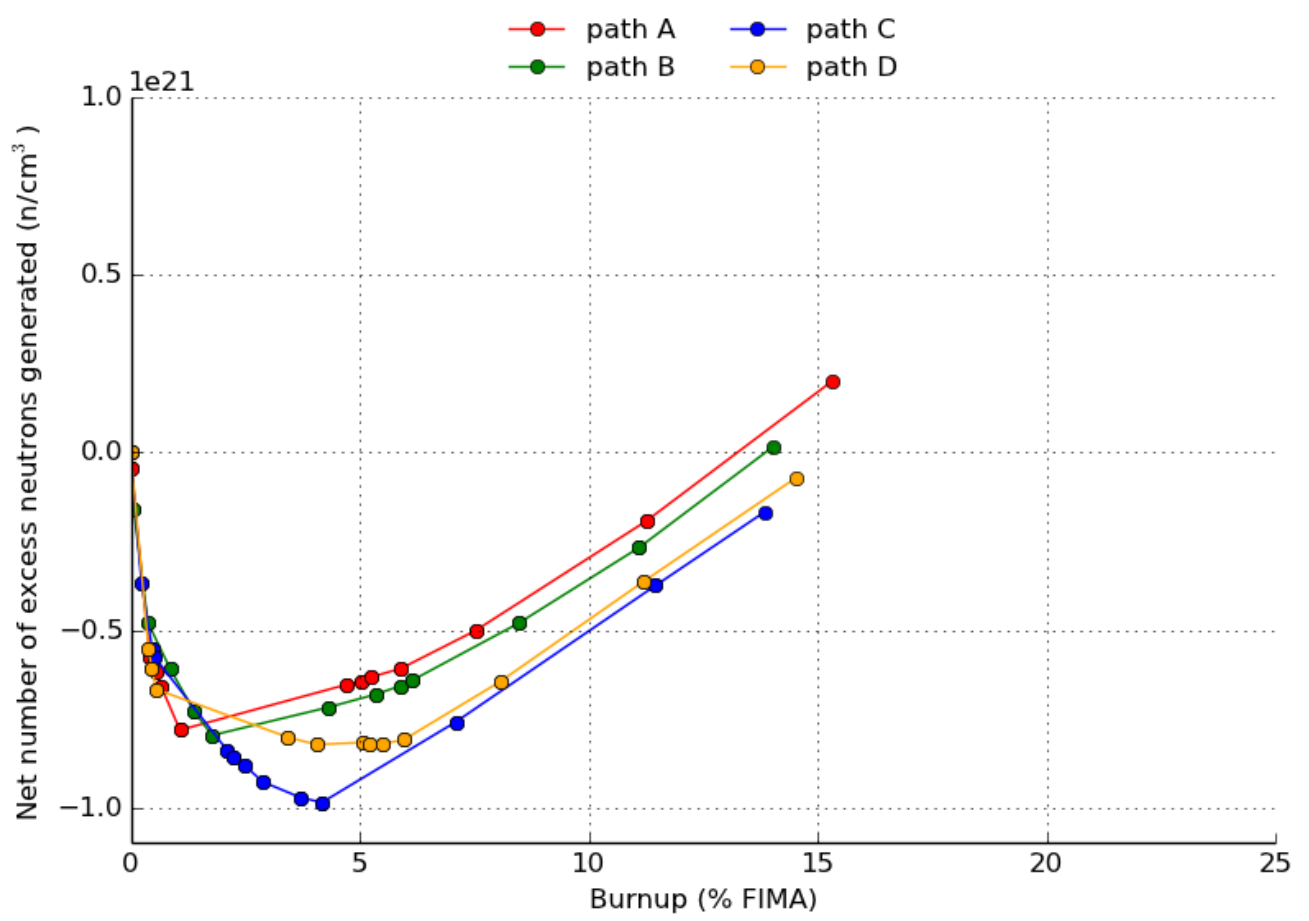

Figure 16 Fuel path dependent neutron balance of 3D shuffling for Design I core. 
In the 2D shuffled reference core, The fuel of path A and B remained a net neutron absorber throughout its residence in the core; the neutron balance of these burnup batches did not even reach the turning point implying that their discharge $k_{\infty}<1.0$. The fuel of path $\mathrm{C}$, although becoming a net neutron producer, did not manage to pay back the number of neutrons it absorbed. Only the axially central fuel path D (and its counterpart E) exceeded the zero balance line and by a large extent as it has to make up for the neutron deficiency of the other three fuel paths.

In the 3D shuffled Design I core on the other hand, the fuel of each of the paths has paid back all or most of the neutrons it absorbed; it's neutron balance at discharge is in the vicinity of zero, as can be seen in Figure 16. This is because the 3D fuel shuffling significantly flattens the burnup distribution of the discharged fuel as can be deduced from the burnup corresponding to the end point of the neutron balance curve of each of the fuel paths shown in Figure 16. The 3D fuel shuffling also significantly increases the average discharge burnup and therefore also the cycle length. The longer cycle increases the positive burnup reactivity swing from $2.81 \%$ of the $2 \mathrm{D}$ to $4.66 \%$ of the $3 \mathrm{D}$ shuffled and therefore also of the fraction of neutrons that are absorbed in the reactivity control system. However, per unit time or given amount of energy generated, the burnup reactivity swing is comparable: $1.09 \%$ versus $0.95 \% \Delta k / k$ per effective full power year (EFPY).

The peak dpa of the fuel discharged from each of the 8 fuel management paths of the 2D and 3D shuffled cores is displayed in Figure 17. In the 2D shuffled core the dpa strongly peaks at the core axial center (Paths D and E) while with 3D fuel shuffling the peak discharge dpa is within $\pm 3 \%$ of the average. 


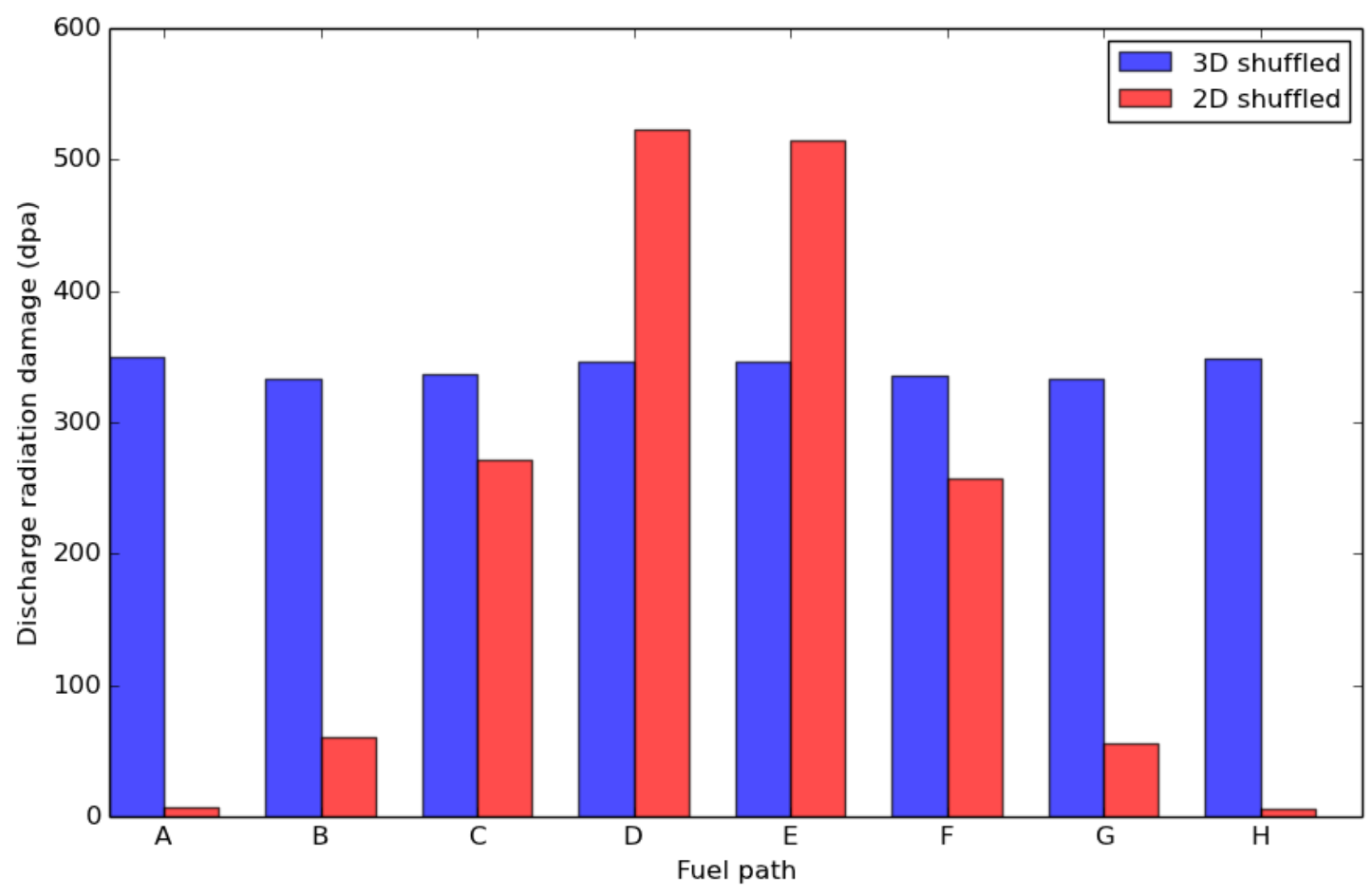

Figure 17 HT-9 discharge dpa for Design I core.

In summary, 3D shuffling offers an increase of $45 \%$ in the average discharge burnup, and hence the fuel utilization, along with a $34 \%$ reduction in the minimum required peak HT-9 dpa - from 534.2 to 351.0 dpa. The 3D shuffled Design I core therefore far outperforms the 2D shuffled reference core on both economics (average burnup and cycle time) and radiation damage. However, the 2D shuffled core provides a less severe reactivity swing over the cycle and a smaller power change within one batch, both of which are direct results of the difference in the SPs.

\section{Sensitivity of Core Performance to Core Design Simplification}

The implementation of the 3D fuel shuffling strategy considered in the previous section will require significantly longer refueling time, more complicated refuelling machine and, possibly, two separate refueling machines to cut down the total refueling time, [11] and larger workspace above the core to disassemble and reassemble the fuel assemblies relative to 2D fuel shuffling. Therefore, a number of design approaches for 3D shuffling simplifications were examined and their effect on the core performance improvements 
relative to $2 \mathrm{D}$ fuel shuffling was quantified.

The first approach to reduce the refueling effort is to avoid shuffling sub-assemblies between fuel assemblies; that is, to restrict the shuffling of sub-assemblies to axial shuffling within the same fuel assembly. [42] Radial shuffling will be performed for entire fuel assemblies as in a 2D shuffling strategy. More specifically, at the refueling outage, a fuel assembly is lifted from the core segment by segment, then reassembled in a different radial location using the same sub-assemblies but in a different axial order. This shuffling strategy will greatly reduce the workspace and time required for refueling. The performance of Design I core using this restricted SP is compared with the reference 3D shuffling strategy in Section 4.

The second approach is to reduce the number of segmented assemblies used to constitute one fuel assembly. Two variants of Design I core were studied; their design parameters are given in Table 4. Design II core is loaded with fuel assemblies made of 3 axially stacked sub-assemblies, each having identical dimensions as of Design I. The active core height is $228 \mathrm{~cm}$ (consisting of 3 segmented rods and 2 volumes of fuel-free space in the axial direction), giving a core volume of $42.70 \mathrm{~m}^{3}$. As will be shown in Section 5.2 , the core thermal power of Design II was adjusted to achieve the same fuel specific power as of Design I, which was $7.22 \mathrm{~kW} / \mathrm{kg}$. The resulting core power was $2340 \mathrm{MW}$, corresponding to a volumetric power density of $54.80 \mathrm{MW} / \mathrm{m}^{3}$, which is slightly lower than that of Design I.

Design III core further reduces the number of sub-assemblies to two per assembly while preserving Design I active fuel length. The fuel length of each sub-assembly was doubled to $140 \mathrm{~cm}$ followed by $7 \mathrm{~cm}$ for fuel axial expansion and venting. The resulting core height is $287 \mathrm{~cm}-14 \mathrm{~cm}$ shorter of Design I core. Again, the core power of $2935 \mathrm{MW}$ was determined by matching the fuel specific power of Design I and III. This yields a slightly lower core volume of $54.71 \mathrm{~m}^{3}$ and volumetric power density of $54.83 \mathrm{MW} / \mathrm{m}^{3}$. The performance of Design II and III cores is given in Section 5.2 and 5.3, respectively.

Table 4 Design parameters of alternative B\&B core designs with 3D fuel shuffling

\begin{tabular}{|l|l|l|l|}
\hline Design Parameter & Design I & Design II & Design III \\
\hline
\end{tabular}




\begin{tabular}{|l|l|l|l|}
\hline Number of sub-assemblies per assembly & 4 & 3 & 2 \\
\hline Total fuel length in assembly $(\mathrm{cm})$ & 280 & 210 & 280 \\
\hline Core thermal power $(\mathrm{MW})$ & 3000 & 2340 & 2935 \\
\hline Active core height $(\mathrm{cm})$ & 301 & 224 & 287 \\
\hline Equivalent core radius $(\mathrm{cm})$ & 246.34 & 246.34 & 246.34 \\
\hline Active core volume $\left(\mathrm{m}^{3}\right)$ & 57.38 & 42.70 & 54.71 \\
\hline Power density $\left(\mathrm{MW} / \mathrm{m}^{3}\right)$ & 56.20 & 54.80 & 53.64 \\
\hline
\end{tabular}

\subsection{Design I Core with Constrained Axial Shuffling}

SA algorithm was employed to search for the optimal 3D SP for Design I B\&B core while restricting the axial shuffling to interchanges in the axial location of the sub-assemblies within the same fuel assembly. The radial shuffling of entire assemblies follows the strategy of the optimal 2D SP for the reference core, as shown in Figure 10, to take advantage of the already improved core performance in addition to further reducing the optimization effort. The optimal SP arrives at is shown in Figure 18. Comparing with the 2D shuffled core, each fuel assembly in this case was reassembled using the same subassemblies but in a different order, which helps flatten the axial profile of burnup and power. 


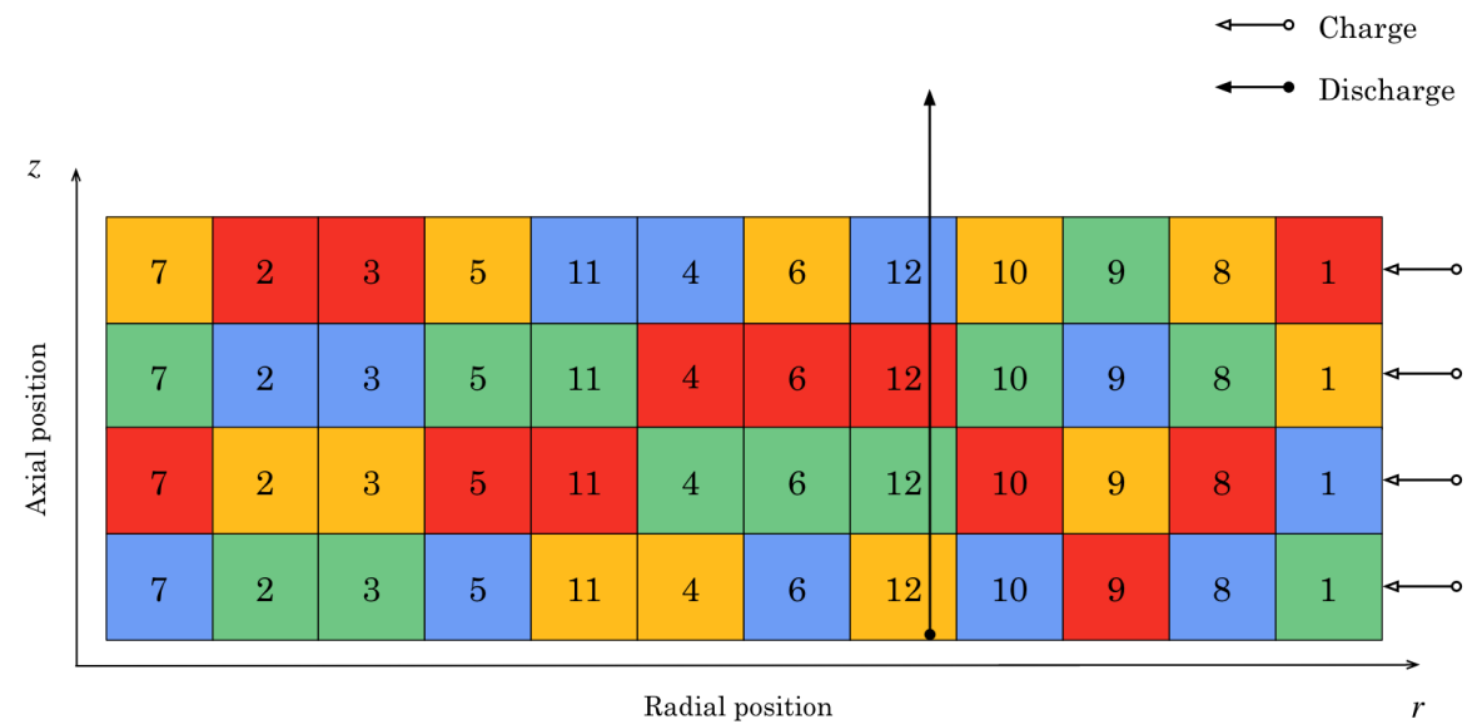

Figure 18 Optimal 3D shuffling pattern for Design I B\&B core with constrained axial shuffling.

The resulting optimal core performance using axially-constrained fuel shuffling is compared with the unconstrained result in Table 5. The equilibrium cycle length and discharge burnup are 1728 EFPD and 16.02\% FIMA respectively, both slightly larger than those of the unconstrained case. By placing high burnup fuel (e.g. batch 11 and 12) at the axial periphery of the core, this shuffling strategy is able to flatten the axial power peaking factor to 1.37 , but inevitably causes a higher axial leakage probability of $3.84 \%$. The radial power peaking factor of 1.78 is slightly higher than the 1.70 of the unrestricted 3D shuffled core. This required to reduce the fuel volume fraction from $39.77 \%$ to $39.27 \%$ in order to meet the thermal-hydraulic constraints. This increase of core leakage and the reduction of fuel volume fraction are the major contributors to the $25 \mathrm{dpa}$ increase in the minimum required peak radiation damage to the HT-9 cladding, when compared with the 3D SP introduced in Section 4 for the same core design.

Table 5 Performance of optimal Design I B\&B core with axially-constrained shuffling

\begin{tabular}{|l|l|l|}
\hline Shuffling type & $\begin{array}{l}\text { 3D axially- } \\
\text { constrained }\end{array}$ & $\begin{array}{l}\text { 3D } \\
\text { unconstrained }\end{array}$ \\
\hline Core thermal power $(\mathrm{MW})$ & 3000 & 3000 \\
\hline Burn cycle time $(\mathrm{EFPD})$ & 1728 & 1566 \\
\hline Burnup reactivity swing $(\% \Delta k / k)$ & 3.26 & 4.66 \\
\hline
\end{tabular}




\begin{tabular}{|c|c|c|c|}
\hline \multicolumn{2}{|c|}{ Average discharge BU (\% FIMA) } & 16.02 & 14.49 \\
\hline \multicolumn{2}{|c|}{ Peak discharge BU (\% FIMA) } & 17.16 & 15.69 \\
\hline \multicolumn{2}{|c|}{ Peak radiation damage (dpa) } & 375.8 & 351.0 \\
\hline \multicolumn{2}{|c|}{ Peak fast fluence $\left(\mathrm{n} / \mathrm{cm}^{2}\right)$} & $9.85 \mathrm{E}+23$ & $9.88 \mathrm{E}+23$ \\
\hline \multicolumn{2}{|c|}{ Axial/radial leakage probability (\%) } & $3.84 / 3.05$ & $1.56 / 2.75$ \\
\hline \multicolumn{2}{|c|}{ Axial/radial power peaking factor } & $1.37 / 1.78$ & $2.00 / 1.70$ \\
\hline \multicolumn{2}{|c|}{ Peak batch power change $(\%)$} & 16.28 & 22.14 \\
\hline \multicolumn{2}{|c|}{ Pitch-to-diameter ratio } & 1.076 & 1.070 \\
\hline \multirow{5}{*}{$\begin{array}{l}\text { Core } \\
\text { volume } \\
\text { fractions } \\
(\%)\end{array}$} & Fuel & 39.27 & 39.77 \\
\hline & Gap & 13.09 & 13.26 \\
\hline & Cladding+Wire & 12.66 & 12.77 \\
\hline & Duct & 6.56 & 6.57 \\
\hline & Coolant & 28.42 & 27.63 \\
\hline
\end{tabular}

\subsection{Design II Core Characteristics}

The SP optimization procedure for Design II core was similar to that described in Section 4, except for the solution update scheme, because the axial symmetry is lost with three segments per fuel assembly. Thus, the preservation of symmetry was removed from the binary fuel exchange strategy. The optimal 3D SP found is given in Figure 19 and the core characteristics are summarized in Table 6 left column of results. The core thermal power of $2340 \mathrm{MW}$ was determined by matching the fuel specific power to that of Design I, which is $7.22 \mathrm{~kW} / \mathrm{kg}$. Therefore, in addition to the fuel volume fraction and radial power peaking factor, the coupled neutronics and thermal-hydraulics calculation scheme as shown in Figure 6 also iterates on specific power in this case. It took four iterations for this case to converge. 


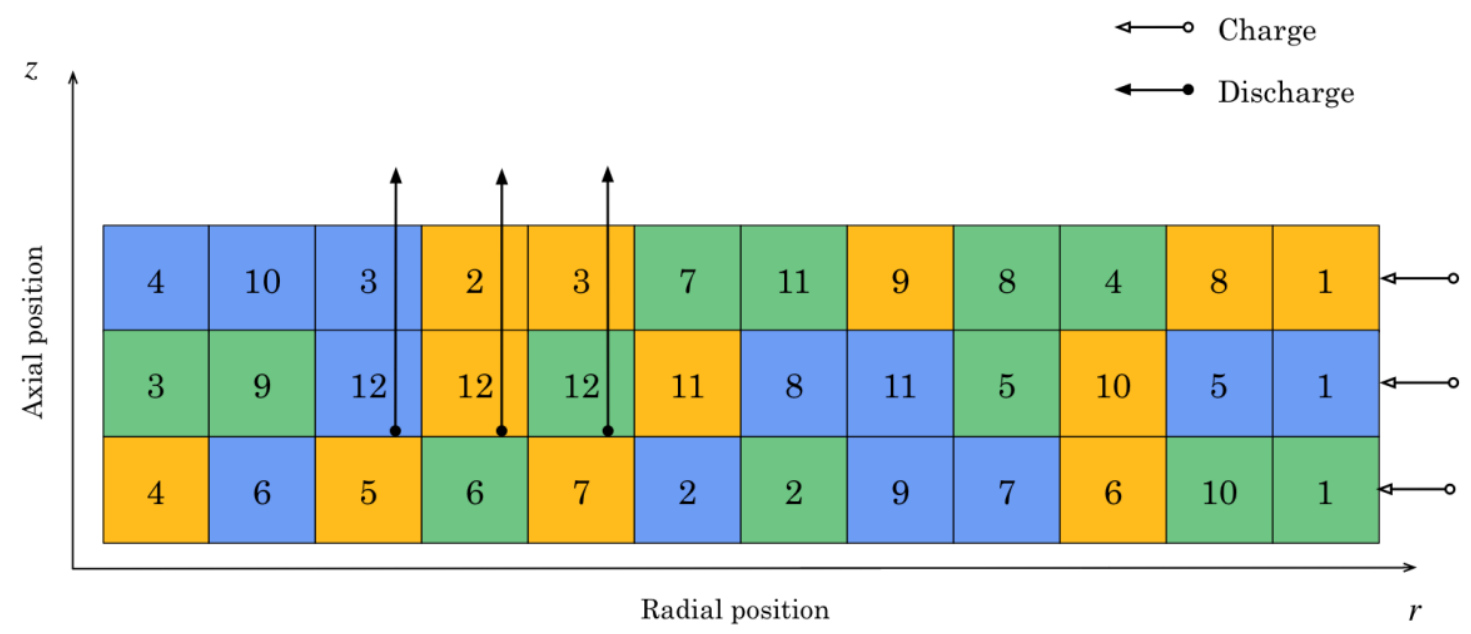

Figure 19 Optimal 3D shuffling pattern for Design II B\&B core.

As can be seen by comparing Table 6 with Table 3, the reduction of the number of axially stacked sub-assemblies from 4 to 3 along with a $25 \%$ reduction in the total active fuel length does not significantly penalize the core performance except for the total core power. The minimum required peak radiation damage is $359.8 \mathrm{dpa}-$ only about $2.5 \%$ higher than of the optimal 3D shuffled Design I core even though the average power density is similar. Due to the reduced core height and therefore reduced pressure drop, the fuel volume fraction could be increased to $41.45 \%$.

Table 6 Performance of Optimal Design II B\&B core with various sub-assembly lengths

\begin{tabular}{|l|l|l|l|}
\hline Active fuel length $(\mathrm{cm})$ & 210 & 180 & 150 \\
\hline Core thermal power $(\mathrm{MW})$ & 2340 & 2078 & 1794 \\
\hline Burn cycle time (EFPD) & 1598 & 1628 & 1756 \\
\hline Burnup reactivity swing $(\% \Delta k / k)$ & 4.85 & 4.44 & 3.96 \\
\hline Average discharge BU (\% FIMA) & 14.64 & 14.91 & 16.03 \\
\hline Peak discharge BU (\% FIMA) & 14.95 & 15.31 & 16.58 \\
\hline Peak fast fluence (n/cm $\left.{ }^{2}\right)$ & $1.19 \mathrm{E}+24$ & $1.19 \mathrm{E}+24$ & $1.19 \mathrm{E}+24$ \\
\hline Axial/radial leakage probability $(\%)$ & $1.72 / 0.89$ & $2.63 / 0.92$ & $4.17 / 0.98$ \\
\hline Peak radiation damage (dpa) & 359.8 & 367.9 & 397.1 \\
\hline Axial/radial power peaking factor & $2.18 / 1.85$ & $2.02 / 1.76$ & $1.85 / 1.63$ \\
\hline Peak batch power change $(\%)$ & 12.19 & 10.45 & 9.27 \\
\hline
\end{tabular}




\begin{tabular}{|l|l|l|l|l|}
\hline \multicolumn{2}{|l|}{ Pitch-to-diameter ratio } & 1.055 & 1.034 & 1.017 \\
\hline \multirow{3}{*}{$\begin{array}{l}\text { Core volume } \\
\text { fractions (\%) }\end{array}$} & Fuel & 41.45 & 42.92 & 44.52 \\
\cline { 2 - 5 } & Gap & 13.82 & 14.31 & 14.84 \\
\cline { 2 - 5 } & Cladding+Wire & 13.13 & 13.50 & 13.94 \\
\cline { 2 - 5 } & Duct & 6.63 & 6.69 & 6.77 \\
\cline { 2 - 5 } & Coolant & 24.96 & 22.58 & 19.93 \\
\hline
\end{tabular}

A trade-off between the height and performance of the 3-subassebly core was studied by designing two additional cores the sub-assembly length of which was reduced from the original $70 \mathrm{~cm}$ to $60 \mathrm{~cm}$ and $50 \mathrm{~cm}$, respectively. All three cases have the same fuel specific power. The results are compared in Table 6.

It was found that shortening of the effective core height from 210 to $150 \mathrm{~cm}$ results in an increase of the fuel volume fraction from $41.45 \%$ to $44.52 \%$ which could not provide enough excess neutrons to fully compensate for the increase of the axial leakage probability from $1.72 \%$ to $4.17 \%$. As a result, the averaged discharge burnup had to be raised from $14.64 \%$ to $16.03 \%$, corresponding to an increase in the equilibrium cycle length from 1598 to 1756 EFPD, and the peak radiation damage has increased by 37.3 dpa. However, the intermediate $180-\mathrm{cm}$ core design presents a well-balanced performance; the peak radiation damage is $367.9 \mathrm{dpa}-$ only $2.3 \%$ increase from the $210-\mathrm{cm}$ core.

\subsection{Design III Core Characteristics}

In Design III core where fuel assemblies were constituted by only 2 segments, any 3D SP can technically be considered as an axially-constrained shuffling scheme as shown in Section 5.1 due to the core symmetry in axial direction. Therefore, the same optimization strategy was applied and the optimal 3D SP is shown in Figure 20. It can be seen that the radial movement of the fuel assemblies follows that of the optimal 2D SP shown in Figure 10 , and the axial locations of the sub-assemblies switch when necessary. In fact, only 4 switches are required for each of the fuel assemblies (at the end of cycle 4, 5, 8, and 10). Provided the refueling machine can handle complete assemblies, it means $2 / 3$ of the shuffling operations does not involve disassembling and reassembling of the fuel assembly, which provides a significant reduction in refueling time and effort, when compared with 
any of the designs investigated so far.

A core thermal power of $2935 \mathrm{MW}$ is required to maintain the fuel specific power of $7.22 \mathrm{~kW} / \mathrm{kg}$. Each sub-assembly has been split into 4 burnup zones so as to have comparable axial burnup resolution as of the previously considered core designs. It was expected that the axial burnup flattening is more challenging in this core design because its sub-assemblies are twice as long.

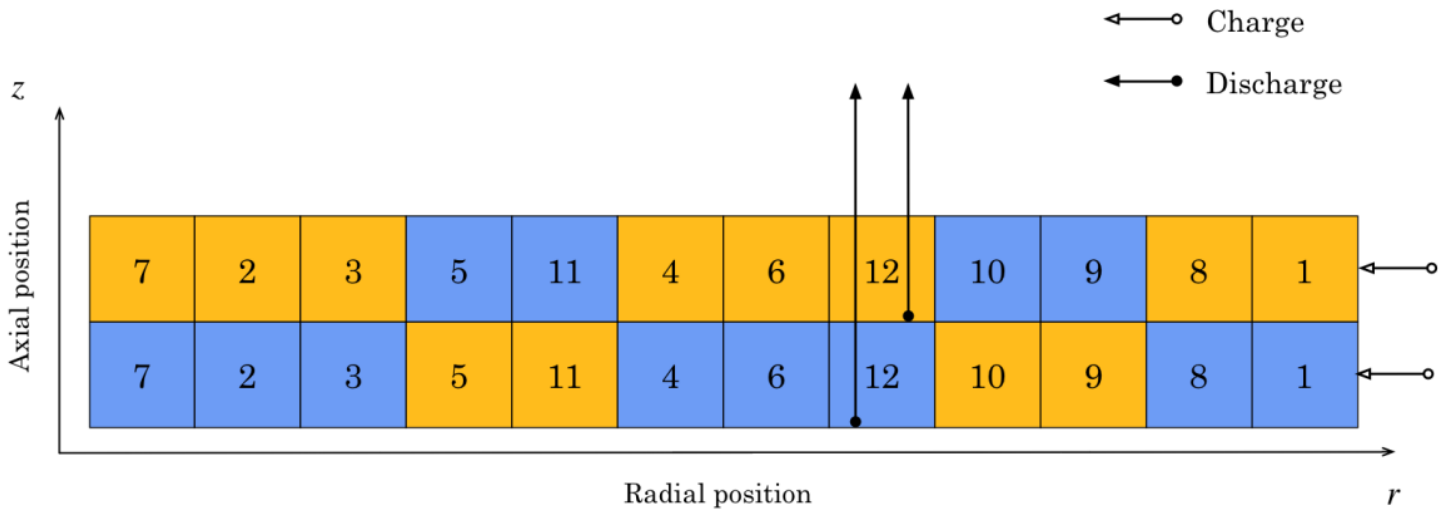

Figure 20 Optimal 3D shuffling pattern for Design III B\&B core.

As a result of the limited axial shuffling, the performance of this core, summarized in Table 7, is degraded as compared to the previous two designs. The peak radiation damage is $402.6 \mathrm{dpa}$ - almost $15 \%$ higher than that of Design I. This is due primarily to the large peak to average peak discharge dpa of 1.20 as compared to 1.03 in Design I cores (for both unconstrained and axially-constrained shuffling cases), as can be seen in Figure 21. Also contributing to increase in minimum required dpa is the relatively high radial power peaking that is forcing a decrease of the fuel inventory resulting in a negative impact on the neutron economy.

Table 7 Design III B\&B core performance with 3D shuffling

\begin{tabular}{|l|l|l|}
\hline Core thermal power (MW) & 2935 & 2338 \\
\hline Active fuel length $(\mathrm{cm})$ & 280 & 210 \\
\hline Burn cycle time (EFPD) & 1584 & 1650 \\
\hline Burnup reactivity swing $(\% \Delta \mathrm{k} / \mathrm{k})$ & 3.88 & 3.90 \\
\hline Average discharge BU (\% FIMA) & 14.49 & 15.09 \\
\hline
\end{tabular}




\begin{tabular}{|c|c|c|c|}
\hline \multicolumn{2}{|c|}{ Peak discharge BU (\% FIMA) } & 17.50 & 17.39 \\
\hline \multicolumn{2}{|c|}{ Peak radiation damage (dpa) } & 402.6 & 404.9 \\
\hline \multicolumn{2}{|c|}{ Peak fast fluence $\left(\mathrm{n} / \mathrm{cm}^{2}\right)$} & $9.89 \mathrm{E}+23$ & $1.02 \mathrm{E}+24$ \\
\hline \multicolumn{2}{|c|}{ Axial/radial leakage probability (\%) } & $2.66 / 3.26$ & $3.82 / 2.97$ \\
\hline \multicolumn{2}{|c|}{ Axial/radial power peaking factor } & $1.31 / 1.86$ & $1.31 / 1.85$ \\
\hline \multicolumn{2}{|c|}{ Peak batch power change $(\%)$} & 16.61 & 18.38 \\
\hline \multicolumn{2}{|c|}{ Pitch-to-diameter ratio } & 1.083 & 1.050 \\
\hline \multirow{5}{*}{$\begin{array}{l}\text { Core volume } \\
\text { fractions }(\%)\end{array}$} & Fuel & 38.97 & 41.45 \\
\hline & Gap & 12.99 & 13.82 \\
\hline & Cladding+Wire & 12.61 & 13.14 \\
\hline & Duct & 6.55 & 6.63 \\
\hline & Coolant & 28.89 & 24.95 \\
\hline
\end{tabular}

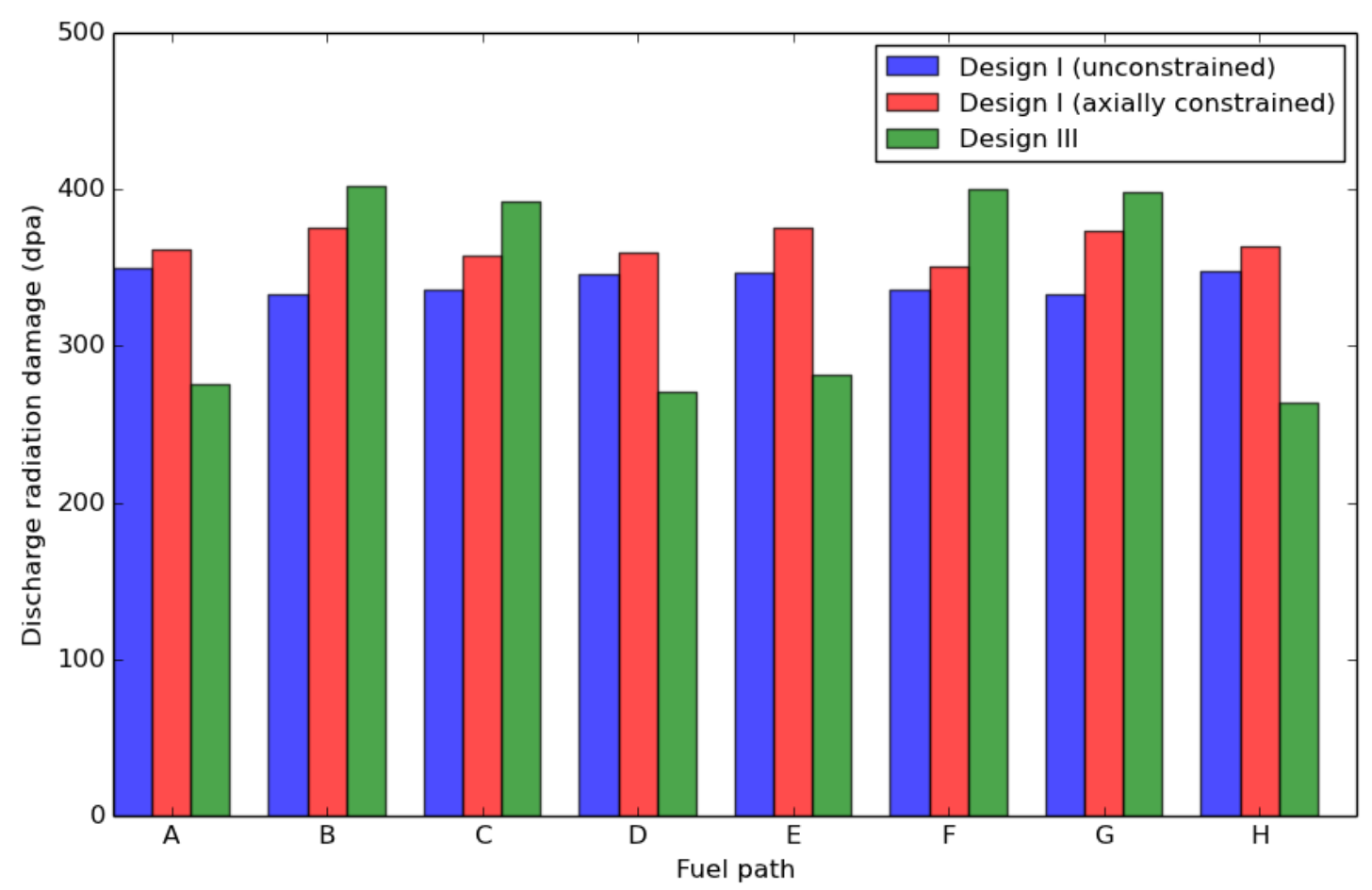

Figure 21 HT-9 discharge dpa for Design III core in comparison with Design I.

A variation of Design III in which the length of the assembly segment was reduced from $140 \mathrm{~cm}$ to $105 \mathrm{~cm}$ was then investigated. As can be seen in Table 7, the overall performance of the shorter core is not much degraded relative to the original design, where the peak radiation damage was only 2.3 dpa higher. This is because the reduced pressure 
drop enables a higher fuel inventory (or smaller P/D ratio) that can partially compensate for the neutron leakage probability - primarily in the axial direction, which increases from $2.66 \%$ to $3.82 \%$. This also results in a slightly larger average discharge burnup in the shorter core. In comparison with the standard Design II core, which has the same active fuel length (210 $\mathrm{cm})$, the peak radiation damage has increased by $45.1 \mathrm{dpa}$ in the shorter core of Design III; however, it is still $25 \%$ lower than that of the reference 2D shuffled core while offering significantly simpler shuffling strategy and less refueling effort, when compared with the previously studies 3D shuffled cores.

\subsection{Effect of Power Density on Optimal Core Performance}

The core designs developed so far are characterized by low power density, which is typical to $\mathrm{B} \& \mathrm{~B}$ cores. The sensitivity of the core performance, especially the peak radiation damage, to the core power density was investigated for Design II core. The results are presented in Table 8 for 2500 MW, 3000 MW and 3500 MW Design II-like cores as compared to the original $2340 \mathrm{MW}$ core. All three cores adopt the same core geometric configuration and optimal SP depicted in Figure 19.

As the core power increases from $2340 \mathrm{MW}$ to $3500 \mathrm{MW}$, a larger coolant flow area is required to meet the thermal hydraulic constraints - in particular the pressure drop, leading to an increase of P/D ratio and decrease of fuel inventory, which harms the neutron economy. As a result of the impaired neutron economy higher fuel burnup is required to sustain the B\&B mode of operation, and consequently, the minimum required peak radiation damage increases with an increase in the core power level. Since in the vicinity of the discharge burnup the reactivity increase with burnup is much smaller than in the low burnup range, the increase of overall fuel burnup when going to a higher power level results in a decrease in the burnup reactivity swing. The impact of core power level on some of the design parameters is illustrated in Figure 22. It can be seen that except for the peak dpa level, all other parameters are slightly improved with power upgrade. Overall it appears desirable to increase the core power level - a $\sim 50 \%$ increase in the power level will result in an additional $10 \%$ increase in fuel utilization and incur a penalty of only a $\sim 6 \%$ increase in the dpa the cladding will have to accommodate. 
Table 8 Sensitivity of Design II B\&B core performance to power density

\begin{tabular}{|c|c|c|c|c|}
\hline \multicolumn{2}{|l|}{ Core design } & $2500 \mathrm{MW}$ & $3000 \mathrm{MW}$ & $3500 \mathrm{MW}$ \\
\hline \multicolumn{2}{|c|}{ Burn cycle time (EFPD) } & 1488 & 1236 & 1062 \\
\hline \multicolumn{2}{|c|}{ Burnup reactivity swing $(\% \Delta \mathrm{k} / \mathrm{k})$} & 4.66 & 4.30 & 3.97 \\
\hline \multicolumn{2}{|c|}{ Average discharge BU (\% FIMA) } & 14.87 & 15.41 & 16.02 \\
\hline \multicolumn{2}{|c|}{ Peak discharge BU (\% FIMA) } & 15.23 & 15.87 & 16.57 \\
\hline \multicolumn{2}{|c|}{ Peak radiation damage (dpa) } & 362.84 & 370.93 & 381.35 \\
\hline \multicolumn{2}{|c|}{ Peak fast fluence $\left(\mathrm{n} / \mathrm{cm}^{2}\right)$} & $1.18 \mathrm{E}+24$ & $1.19 \mathrm{E}+24$ & $1.20 \mathrm{E}+24$ \\
\hline \multicolumn{2}{|c|}{ Axial/radial leakage probability $(\%)$} & $1.84 / 0.96$ & $2.07 / 1.09$ & 2.30/1.21 \\
\hline \multicolumn{2}{|c|}{ Axial/radial power peaking factor } & $2.15 / 1.81$ & $2.10 / 1.75$ & $2.04 / 1.69$ \\
\hline \multicolumn{2}{|c|}{ Peak batch power change (\%) } & 12.08 & 11.92 & 11.37 \\
\hline \multicolumn{2}{|c|}{ Pitch-to-diameter ratio } & 1.055 & 1.074 & 1.093 \\
\hline \multirow{5}{*}{$\begin{array}{l}\text { Core volume } \\
\text { fractions (\%) }\end{array}$} & Fuel & 40.99 & 39.44 & 37.99 \\
\hline & Gap & 13.66 & 13.15 & 12.66 \\
\hline & Cladding+Wire & 13.03 & 12.69 & 12.42 \\
\hline & Duct & 6.61 & 6.56 & 6.52 \\
\hline & Coolant & 25.71 & 28.16 & 30.41 \\
\hline
\end{tabular}




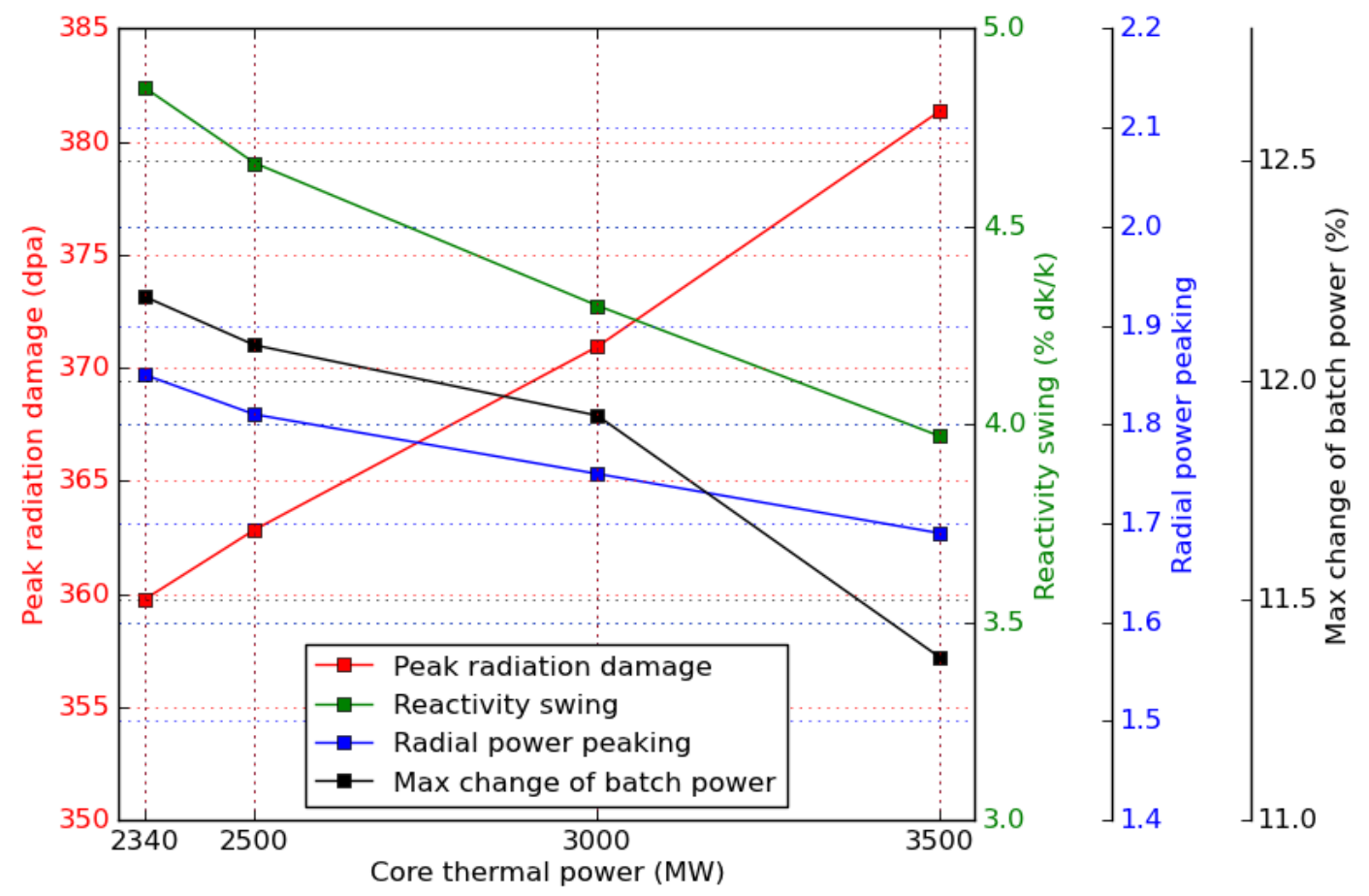

Figure 22 Optimal core performance of Design II as a function of core power.

\section{Conclusions}

This paper presents the development and implementation of a combinatorial optimization search methodology of 3D shuffling pattern (SP) based on the Simulated Annealing (SA) algorithm for self-sustaining B\&B reactors. The automated search for the optimal SP was performed using coupled neutronics and thermal-hydraulics code system consisting of the deterministic neutronics ARC code package developed by ANL coupled with the in-house developed ADOPT code for the thermal-hydraulics and structural design of fuel assemblies. The developed methodology was found to be very effective in identifying optimal SP some of which were counterintuitive - for example, featuring a relatively large neutron leakage probability - a performance characteristics that we tried to minimize when using a trialand-error search [5]. Moreover, in addition to minimizing the peak dpa level the SA-based optimization search methodology was found capable of improving a number of performance characteristics including reducing the burnup reactivity swing, the radial power peaking factor and the relative change in the assembly power over a cycle. 
Compared with the optimal conventional 2D fuel shuffling, the optimal 3D SP offers a 34\% reduction of the peak radiation damage level, down to 350 dpa; a 45\% increase in the average fuel discharge burnup, and hence the uranium utilization, without violating all major neutronics and thermal-hydraulics constraints. For the same peak dpa level, the average discharge burnup of the 3D shuffled core is 2.23 times that of the $2 \mathrm{D}$ shuffled core; this corresponds to a $\sim 120 \%$ relative increase in the fuel utilization. These significant improvements may enable an earlier commercialization of $\mathrm{B} \& \mathrm{~B}$ reactors than otherwise. In the long term, the successful deployment of the B\&B core along with optimal 3D shuffling of fuel could provide at least 25-fold increase in uranium utilization over current once-through LWRs, and hence significantly improve the sustainability of the oncethrough nuclear fuel cycle.

The introduction of the axially segmented fuel assembly design will inevitably increase the complexity of refueling strategy, and will increase refueling time. A number of variations of the standard 3D shuffled design approach to alleviate these drawbacks were examined. The first approach was to restrict the shuffling of sub-assemblies to axial shuffling within the same fuel assembly. It was found that this approach can flatten the radiation damage distribution of the discharge fuel to the same level of the unconstrained 3D shuffling, but it also increases the core leakage and therefore causes an increase in the peak radiation damage from 351 to $376 \mathrm{dpa}$.

The second approach is to reduce the number of sub-assemblies used to constitute a single fuel assembly. It was found that by reducing the number of segments from 4 to 3 , i.e., reducing the active fuel length by $25 \%$, the core performance was not significantly degraded except for the core power. The minimum required peak radiation damage was increased by only $2.5 \%$, while other performance parameters were similar, when compared with the 4-segments fuel assembly design with unconstrained 3D fuel shuffling. When the number of fuel segments in each fuel assembly was reduced to 2, the core designs were challenged for the ability to flatten the axial burnup distribution of the discharge fuel. As a result, the peak radiation damage level was $\sim 400 \mathrm{dpa}$, which is nearly $15 \%$ higher than that of the 4 subassembly per assembly core but still offers $\sim 25 \%$ reduction compared with the 
optimal 2D shuffling case. More importantly, a much simpler shuffling strategy and significantly less refueling effort could be achieved using this design approach.

The impact of power level increase on the minimum required peak dpa level was investigated for Design II core. It was found that a 50\% increase in the power level (or power density) will require only a $\sim 6 \%$ increase in the peak dpa the cladding will have to accommodate.

While offering significant improvements of the B\&B core performance as discussed above, the 3D fuel shuffling also gives rise to a number of mechanical feasibility issues. First, the segmented fuel assembly design requires further evaluation and optimization. The venting fixtures on top of the sub-assembly has to be carefully designed and the gaseous fission products vented into the reactor primary loop has to be properly handled.

Dimensional changes to the connecting pieces must be small enough to ensure adequate attachment and detachment of assembly segments throughout the lifetime of the core, without exceeding withdrawal-force limits of the shuffling machine itself.

Second, a refueling machine and strategies have to be designed for disconnecting sub-assemblies and reconnecting them to make new assemblies. Even using only 2 segmented assemblies will cause a considerable increase in the time and workspace required for fuel handling. Thus, a cost/benefit analysis must be performed in order to assess the tradeoff between the improved core performance versus the complexity in fuel handling devices and increased reactor downtime and a corresponding decrease in the nuclear plant capacity factor. A refueling machine with the capability of transferring more than one assembly segments at a time can be a potential solution to reduce the down time associated with fuel shuffling. [43] Another possible approach currently under study is to increase the lateral dimension of the fuel segment while decreasing the number of segments required to constitute a full-length assembly, as such the quantity of fuel segments in the core can be significantly reduced.

Another important feasibility issue is to design a B\&B core to be passively safe; the large low-leakage core features a larger positive coolant temperature reactivity coefficient and coolant voiding reactivity feedback [44] than conventional fast reactor cores. Novel 
negative reactivity insertion systems passively actuated by coolant temperature increase may be required to compensate for the low-leakage reactivity effects. [45]

The stochastic optimization method based on the SA algorithm can be further improved: the cooling schedule used in the current study is based on the exponential multiplicative schedule, which is somewhat simplified and may not be the most effective one for this type of problem. An optimal cooling schedule will be selected for future studies from a problem dependent comparative study of different schedules and used in future SP optimizations.

\section{Acknowledgements}

This research is being performed using funding received from the DOE Office of Nuclear Energy's Nuclear Energy University Programs. The technical assistance and feedback of

experts at the Argonne National Laboratory (ANL) is highly appreciated. In particular, the authors would like to thank Dr. Florent Heidet for his assistance. 


\section{References}

[1] H. Sekimoto and K. Ryu, "A New Reactor Burnup Concept "CANDLE”," in Proc. of PHYSOR 2000, Pittsburgh, PA, USA, 2000.

[2] E. Teller, M. Ishikawa and L. Wood, "Completely automated nuclear reactors for longterm operation II," in In Proceeding of ICENES'96, International Conference on Emerging Nuclear Energy Systems, Obninsk, Russia, 1996.

[3] C. Ahlfeld, T. Burke, T. Ellis, P. Hejzlar, K. Weaver, C. Whitmer and J. Gilleland, “Conceptual design of a 500 MWe traveling wave demonstrator reactor plant," in Proc. ICAPP 2011, Nice, France, 2011.

[4] P. Hejzlar, R. Petroski, J. Cheatham, N. Touran, M. Cohen, B. Truong, R. Latta, M. Werner, T. Burke, J. Tandy, M. Garrett, B. Johnson, T. Ellis, J. McWhirter, A. Odedra, P. Schweiger, D. Adkisson and J. Gilleland, “TerraPower, LLC Traveling Wave Reactor Development Program Overview," in Proceedings of ICAPP 2013, Jeju Island, Korea, 2013.

[5] J. Hou, S. Qvist and E. Greenspan, "3-D fuel shuffling for reduced peak burnup and increased uranium utilization of breed-and-burn reactors," in Proceedings of ICAPP 2015, Nice, France, 2015.

[6] M. B. Toloczko, F. A. Garner and C. R. Eiholzer, "Irradiation creep and swelling of the US fusion heats of HT9 and 9Cr-1Mo to 208 dpa at $\sim 400^{\circ}$ C," Journal of Nuclear Materials, Vols. 212-215, pp. 604-607, 1994.

[7] E. Greenspan and F. Heidet, "Energy Sustainability and Economic Stability with 
Breed and Burn Reactors," Progress in Nuclear Energy, vol. 53, pp. 794-799, 2011.

[8] C. Di Sanzo, J. Cohen, T. Cisneros, B. Ludewight and E. Greenspan, “An Accelerator Driven Energy Multiplier for Doubling Uranium Ore Utilization," in Proc. of Accelerator Application Topical Meeting, Knoxville, TN, US, 2011.

[9] G. Zhang, E. Greenspan, A. Jolodosky and J. Vujic, "SFR with Once-through Depleted Uranium Breed \& Burn Blanket," Progress in Nuclear Energy, 2014.

[10] S. Qvist and E. Greenspan, "3D shuffling in Breed and Burn reactors," in American Nuclear Society Winter Meeting, Anaheim, CA, USA, 2014.

[11] S. Qvist, J. Hou and E. Greenspan, "Design and performance of breed-and-burn reactors," Annal of Nuclear Energy, vol. 85, pp. 93-114, 2015.

[12] P. Poon and G. Parks, “Application of genetic algorithms to in-core nuclear management optimization," in Proc. Joint Int. Conf. Mathematical Methods Supercomputing Nuclear Applications, Karlsruhe, Germany, 1993.

[13] M. DeChaine and M. Feltus, "Nuclear fuel management optimization using genetic algorithms," Nucl. Tech., vol. 111, pp. 109-114, 1995.

[14] G. Parks, "Multiobjective pressurized water reactor reload core design by nondominated genetic algorithm search," Nucl. Sci. Eng., vol. 124, pp. 178-187, 1996.

[15] V. G. Toshinsky, H. Sekimoto and G. I. Toshinsky, "Multiobjective fuel management optimization for Self-Fuel-Providing LMFBR using genetic algorithms," Annals of Nuclear Energy, vol. 26, no. 9, pp. 783-802, 1999.

[16] V. Toshinsky, H. Sekimoto and G. Toshinsky, "A method to improve multiobjective genetic algorithm optimization of a self-fuel-providing LMFBR by niche induction 
among nondominated solutions," Annals of Nuclear Energy, vol. 27, pp. 397-410, 2000.

[17] P. J. Turinsky and G. T. Parks, “Advances in nuclear fuel management for light water reactors," Advances in Nuclear Science and Technology, pp. 137-165, 1999.

[18] J. G. Stevens, K. S. Smith, K. R. Rempe and T. J. Downar, “Optimization of pressurized water reactor shuffling by simulated annealing with heuristics," Nuclear science and engineering, vol. 121, no. 1, pp. 67-88, 1995.

[19] T. K. Park, H. G. Joo, C. H. Kim and H. C. Lee, "Multiobjective loading pattern optimization by simulated annealing employing discontinuous penalty function and screening technique," Nuclear Science and Engineering, vol. 162, no. 2, pp. 134-147, 2009.

[20] G. L. O'Neill, “Safety and Economic Aspects of Vented Fuel in Sodium-Cooled Reactors,", in Proceedings of the Conference on Safety, Fuels, and Core Design in Large Fast Power Reactors, 1965.

[21] F. Heidet and E. Greenspan, "Performance of large breed-and-burn core," Nuclear Technoloogy, vol. 181, p. 381, 2013.

[22] H. Ryu, B. O. Lee, S. J. Oh, J. H. Kim and C. B. Lee, "Performance of FCCI barrier foils for U-Zr-Z metallic fuel," Journal of Nuclear Materials, vol. 392, no. 2, pp. 206$212,2009$.

[23] J. A. Horak, J. H. Kittel and F. L. Yaggee, "Irradiation behavior of restrained and vented uranium-2 w/o zirconium alloy," Argonne, IL, US, 1962.

[24] K. L. Derstine, "DIF3D: A Code to Solve One-, Two-, and Three-Dimensional Finite 
Difference Diffusion Theory Problems," 1984.

[25] B. L. Toppel, “A User's Guide to the REBUS-3 Fuel Cycle Analysis Capability,” 1983.

[26] C. H. Lee and W. S. Yang, "MC2-3: Multigroup Cross Section Generation Code for Fast Reactor Analysis," 2013.

[27] R. E. Alcouffe, F. W. Brinkley, D. R. Marr and R. D. O'Dell, 'User's Guide for TWODANT: A Code Package for Two-Dimensional, Diffusion-Accelerated, Neutral Particle Transport," 1990.

[28] J. Hou, F. Heidet, P. Gorman and E. Greenspan, “On Multi-Group Cross Sections for Breed-and-Burn Reactors," in Transaction of the American Nuclear Society, Anaheim, CA, 2014.

[29] M. R. I. T. M.J. Norgett, “A Proposed Method of Calculating Displacement Dos Rates," Nucl. Eng. and Design, vol. 33, pp. 50-54, 1975.

[30] L. Greenwood, "SPECOMP calculations of radiation damage in compounds," in Sixth ASTM-EURATOM Symposium on Reactor Dosimetry, Jackson Hole, WY, 1987.

[31] J. Leppänen, “Serpent Monte Carlo Physics Code," in AER Symposium on VVER Reactor Physics and Reactor Safety, Espoo, Finland, 2010.

[32] S. Qvist and E. Greenspan, "The ADOPT code for automated fast reactor design," Annals of Nuclear Energy, vol. 71, pp. 23-36, 2014.

[33] "Fast Reactor Database 2006 Update," 2006.

[34] A. Suspluagas and E. Greenspan, "Implementation of the ENHS Thermal Hydraulic Optimization Code for Recent ENHS Design Improvement," University of California, 
Berkeley, 2005.

[35] A. Bleise, P. Danesi and W. Burkart, "Properties, use and health effects of depleted uranium (DU): a general overview," Journal of Environmental Radioactivity, vol. 64, no. 2-3, pp. 93-112, 2003.

[36] N. Metropolis, A. Rosenbluth, M. Rosenbluth, A. Teller and E. Teller, "Equation of State Calculations by Fast Computing Machines," J. Chem. Phys., vol. 21, p. 1087, 1953.

[37] S. Kirkpatrick and M. P. Vecchi, "Optimization by simmulated annealing," Science, vol. 220, no. 4598, pp. 671-680, 1983.

[38] K. A. Dowsland and C. R. Reeves, Morden Heuristic Techniques for Combinatorial Problems, McGraw-Hill, 1995.

[39] E. Aarts and J. Korst, Simulated Annealing and Boltzmann Machines: A Stochastic Approach to Combinatorial Optimization and Neural Computing, Chichester: John Wiley \& Sons, 1989.

[40] F. Heidet, R. Petroski and E. Greenspan, "Minimum burnup required for sustainable operation of fast reactors without recycling," in Proceedings International Conference on Fast Reactors and Related Fuel Cycles: Challenges and Opportunities-FR09, Kyoto, Japan, 2009.

[41] F. Heidet and E. Greenspan, "Neutron Balance Analysis for Sustainability of Breedand-Burn Reactors," Nuclear Science and Engineering, vol. 171, no. 1, pp. 13-31, 2012.

[42] A. Dubberley, Private communication. 
[43] R. Meuschke and L. Malandra, "Refueling machine". US Patent 5,687,207, 111997.

[44] S. Qvist and E. Greenspan, "Inherent safety of minimum-burnup breed \& burn reactors," in Proc. of ICAPP 2012, Chicago, IL, US, 2012.

[45] S. Qvist and E. Greenspan, "An Autonomous Reactivity Control System for Improved Fast Reactor Safety," Progress in Nuclear Energy, vol. 77, pp. 32-47, 2014. 